\title{
Colorectal polypectomy and endoscopic mucosal resection (EMR): European Society of Gastrointestinal Endoscopy (ESGE) Clinical Guideline
}

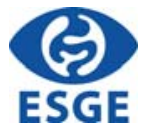

\section{Authors}

Monika Ferlitsch', ${ }^{1,2}$, Alan Moss $s^{3,4}$, Cesare Hassan ${ }^{5}$, Pradeep Bhandari $^{6}$, Jean-Marc Dumonceau ${ }^{7}$, Gregorios Paspatis ${ }^{8}$, Rodrigo Jover $^{9}$, Cord Langner ${ }^{10}$, Maxime Bronzwaer ${ }^{11}$, Kumanan Nalankilli ${ }^{3,4}$, Paul Fockens ${ }^{11}$, Rawi Hazzan ${ }^{12}$, Ian M. Gralnek ${ }^{12}$, Michael Gschwantler ${ }^{2}$, Elisabeth Waldmann ${ }^{1,2}$, Philip Jeschek ${ }^{1,2}$, Daniela Penz ${ }^{1,2}$, Denis Heresbach ${ }^{13}$, Leon Moons ${ }^{14}$, Arnaud Lemmers ${ }^{15}$, Konstantina Paraskeva ${ }^{16}$, Juergen Pohl17, Thierry Ponchon ${ }^{18}$, Jaroslaw Regula ${ }^{19}$, Alessandro Repici ${ }^{20}$, Matthew D. Rutter ${ }^{21}$, Nicholas G. Burgess ${ }^{22,23}$, Michael J. Bourke22,23

Institutions

1 Department of Internal Medicine III, Division of Gastroenterology and Hepatology, Medical University of Vienna, Austria

2 Quality Assurance Working Group of the Austrian Society of Gastroenterology and Hepatology

3 Department of Endoscopic Services, Western Health, Melbourne, Australia

4 Department of Medicine, Melbourne Medical School Western Precinct, The University of Melbourne, St. Albans, Victoria, Australia

5 Digestive Endoscopy Unit, Nuovo Regina Margherita Hospital, Rome, Italy

6 Solent Centre for Digestive Diseases, Queen Alexandra Hospital, Portsmouth, UK

7 Gedyt Endoscopy Center, Buenos Aires, Argentina

8 Department of Gastroenterology, Benizelion General Hospital, Heraklion, Crete, Greece

9 Unidad de Gastroenterología, Servicio de Medicina Digestiva, Instituto de Investigación Sanitaria ISABIAL, Hospital General Universitario de Alicante, Alicante, Spain

10 Department of Pathology, Medical University of Graz, Graz, Austria

11 Department of Gastroenterology, Academic Medical Center, University of Amsterdam, Amsterdam, The Netherlands

12 Institute of Gastroenterology and Hepatology, Ha'Emek Medical Center, Afula, Israel and Rappaport Family Faculty of Medicine Technion-Israel Institute of Technology, Haifa, Israel

13 Department of Digestive Endoscopy, University Hospital, CHU Fort de France, France

14 Department of Gastroenterology and Hepatology, University Medical Center Utrecht, Utrecht, Netherlands

15 Department of Gastroenterology, Hepatopancreatology and Digestive Oncology, Erasme Hospital, Université Libre de Bruxelles (ULB), Brussels, Belgium

16 Konstantopoulio General Hospital, Athens, Greece

17 Department of Gastroenterology, Asklepios Klinik Altona, Hamburg, Germany

18 Department of Endoscopy and Gastroenterology, Edouard Herriot Hospital, Lyon, France
19 Department of Gastroenterology, Maria Sklodowska-Curie Memorial Cancer

Center and Medical Centre for Postgraduate Education, Warsaw, Poland

20 Humanitas Research Hospital, Humanitas University, Rozzano, Milan, Italy

21 School of Medicine, Pharmacy and Health, Durham University, Durham, UK

22 Department of Gastroenterology and Hepatology, Westmead Hospital, Sydney, Australia

23 University of Sydney, Sydney, Australia

\section{Bibliography}

DOI http://dx.doi.org/10.1055/s-0043-102569

Published online: 17.2.2017 | Endoscopy 2017; 49: 270-297

(c) Georg Thieme Verlag KG Stuttgart · New York

ISSN 0013-726X

Corresponding author

Monika Ferlitsch, MD, Division of Gastroenterology and Hepatology, Department of Internal Medicine III, Medical University of Vienna, Waehringer Guertel 18-20, A-1090 Vienna, Austria

Fax: +43-40400-47350

monika.ferlitsch@meduniwien.ac.at

丹 Appendix e1, e2

Online content viewable at: https://www.thieme-connect.com/ DOI/DOI?10.1055/s-0043-102569

\section{MAIN RECOMMENDATIONS}

1 ESGE recommends cold snare polypectomy (CSP) as the preferred technique for removal of diminutive polyps (size $\leq 5 \mathrm{~mm}$ ). This technique has high rates of complete resection, adequate tissue sampling for histology, and low complication rates. (High quality evidence, strong recommendation.)

2 ESGE suggests CSP for sessile polyps $6-9 \mathrm{~mm}$ in size because of its superior safety profile, although evidence comparing efficacy with hot snare polypectomy (HSP) is lacking. (Moderate quality evidence, weak recommendation.)

3 ESGE suggests HSP (with or without submucosal injection) for removal of sessile polyps $10-19 \mathrm{~mm}$ in size. In most cases deep thermal injury is a potential risk and thus submucosal injection prior to HSP should be considered. (Low quality evidence, strong recommendation.)

4 ESGE recommends HSP for pedunculated polyps. To prevent bleeding in pedunculated colorectal polyps with head $\geq 20 \mathrm{~mm}$ or a stalk $\geq 10 \mathrm{~mm}$ in diameter, ESGE recommends pretreatment of the stalk with injection of dilute adrenaline and/or mechanical hemostasis. (Moderate quality evidence, strong recommendation.) 
5 ESGE recommends that the goals of endoscopic mucosal resection (EMR) are to achieve a completely snare-resected lesion in the safest minimum number of pieces, with adequate margins and without need for adjunctive ablative techniques. (Low quality evidence; strong recommendation.)

6 ESGE recommends careful lesion assessment prior to EMR to identify features suggestive of poor outcome. Features associated with incomplete resection or recurrence include lesion size $>40 \mathrm{~mm}$, ileocecal valve location, prior failed attempts at resection, and size, morphology, site, and access (SMSA) level 4. (Moderate quality evidence; strong recommendation.)

7 For intraprocedural bleeding, ESGE recommends endoscopic coagulation (snare-tip soft coagulation or coagulating forceps) or mechanical therapy, with or without the combined use of dilute adrenaline injection. (Low quality evidence, strong recommendation.)

An algorithm of polypectomy recommendations according to shape and size of polyps is given ( $>$ Fig. 1 ).
This Guideline is an official statement of the European Society of Gastrointestinal Endoscopy (ESGE). The Grading of Recommendations Assessment, Development, and Evaluation (GRADE) system was adopted to define the strength of recommendations and the quality of evidence.

\section{Introduction}

The endoscopic removal of colorectal polyps reduces the incidence and mortality of colorectal cancer (CRC) and is considered an essential skill for all endoscopists who perform colonoscopy [1-3]. Various polypectomy techniques and devices are available, their use often varying based on local preferences and availability [4-6]. This evidence-based Guideline was commissioned by the European Society of Gastrointestinal Endoscopy (ESGE). It addresses all major issues concerning the practical use of polypectomy and endoscopic mucosal resection (EMR), to inform and underpin this fundamental technique in colonoscopy and in CRC prevention.

This Guideline does not address management of anticoagulants and other medications in the periprocedural setting, nor post-polypectomy surveillance or quality measurements, as these are addressed in separate Guidelines [7-9].

\section{Methods}

The European Society of Gastrointestinal Endoscopy (ESGE) commissioned this Guideline and appointed a Guideline leader (M. F.) who invited the listed authors to participate in the project development. The key questions were prepared by the coordinating team (M.F, A.M., M.J.B., C.H.) and then approved by the other members. The coordinating team formed task force subgroups, each with its own leader, and divided the key topics (polyp classification, polypectomy for polyps sized $<20 \mathrm{~mm}$, EMR for polyps $\geq 20 \mathrm{~mm}$, technical considerations, adverse events, histopathology) among these task forces (see Appendix 1, available online in Supplementary material).

Each task force performed a systematic literature search to prepare evidence-based and well-balanced statements on their assigned key questions. Searches were performed in Medline. Articles were first selected by title; their relevance was then confirmed by review of the corresponding manuscripts, and articles with content that was considered irrelevant were excluded. Evidence tables were generated for each key question, summarizing the evidence of the available studies (see Appendix 2, available online in Supplementary material). For important out-

\begin{tabular}{|c|c|}
\hline \multicolumn{2}{|c|}{ ABBREVIATIONS } \\
\hline ASGE & $\begin{array}{l}\text { American Society for Gastrointestinal Endos- } \\
\text { copy }\end{array}$ \\
\hline CBF & cold biopsy forceps \\
\hline $\mathrm{Cl}$ & confidence interval \\
\hline CRC & colorectal cancer \\
\hline CSP & cold snare polypectomy \\
\hline EMR & endoscopic mucosal resection \\
\hline ESD & endoscopic submucosal dissection \\
\hline ESGE & European Society of Gastrointestinal Endoscopy \\
\hline FICE & $\begin{array}{l}\text { flexible spectral imaging color enhancement } \\
\text { (also Fuji Intelligent Chromo Endoscopy) }\end{array}$ \\
\hline GRADE & $\begin{array}{l}\text { Grading of Recommendations Assessment, } \\
\text { Development and Evaluation }\end{array}$ \\
\hline HBF & hot biopsy forceps \\
\hline \multicolumn{2}{|c|}{ HD-WLE high definition white light endoscopy } \\
\hline HSP & hot snare polypectomy \\
\hline IPB & intraprocedural bleeding \\
\hline I-SCAN & $\begin{array}{l}\text { i-SCAN digital contrast (Pentax; image proces- } \\
\text { sing providing digital image-enhanced endos- } \\
\text { copy [IEE]) }\end{array}$ \\
\hline LSL & laterally spreading lesion \\
\hline LST & laterally spreading tumor \\
\hline MP & muscularis propria \\
\hline NBI & narrow-band imaging \\
\hline NICE & $\begin{array}{l}\text { NBI International Colorectal Endoscopic } \\
\text { Classification }\end{array}$ \\
\hline NPV & negative predictive value \\
\hline PEC & prophylactic endoscopic coagulation \\
\hline PPB & post polypectomy bleeding \\
\hline PPV & positive predictive value \\
\hline RCT & randomized controlled trial \\
\hline $\mathbf{R} \mathbf{R}$ & relative risk \\
\hline SMI & submucosal invasion \\
\hline SMSA & size, morphology, site, and access \\
\hline STSC & snare-tip soft coagulation \\
\hline TEMS & transanal endoscopic microsurgery \\
\hline WHO & World Health Organization \\
\hline WLE & white light endoscopy \\
\hline
\end{tabular}

comes, articles were individually assessed by the level of evidence and strength of recommendation according to the Grading of Recommendations Assessment, Development, and Evaluation (GRADE) system $[10,11]$. 


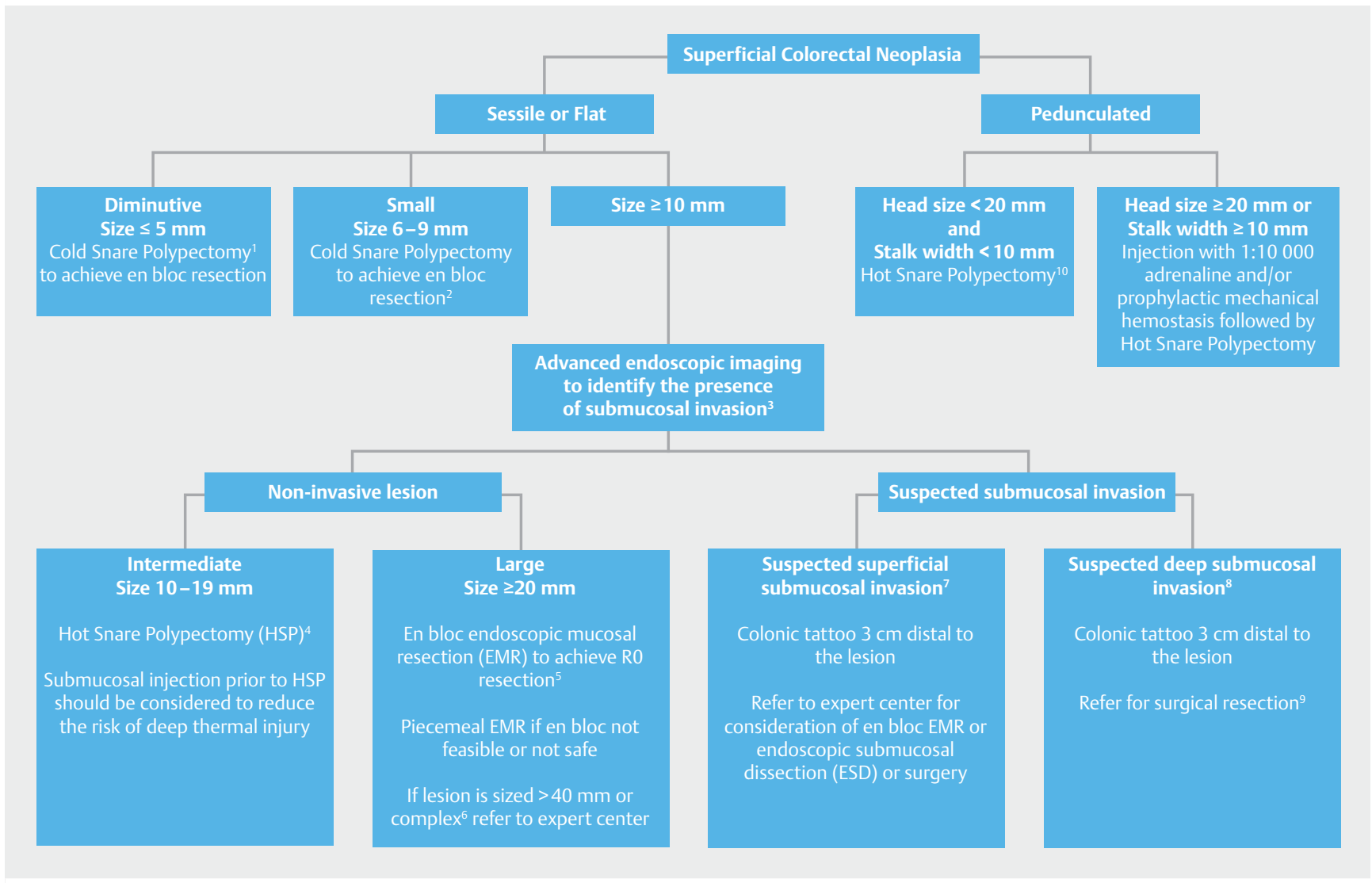

- Fig. 1 Recommended resection techniques for colorectal polyps according to shape and size. ${ }^{1}$ Cold biopsy forceps could be considered as a second-line option, but should only be used for polyps of size $\leq 3 \mathrm{~mm}$ where cold snare polypectomy (CSP) is technically difficult. ${ }^{2}$ When en bloc resection is not achieved, oligo-piecemeal excision is acceptable; however complete retrieval of specimens for histology is necessary. ${ }^{3}$ Standard chromoendoscopy if advanced endoscopic imaging is not available. ${ }^{4}$ Piecemeal cold snare resection may be considered in cases where risk of deep thermal injury is high or unable to be tolerated, but further evidence of efficacy is required. ${ }^{5}$ This may be feasible for lesions of size $\leq 25 \mathrm{~mm}$ and especially those in the left colon or rectum. ${ }^{6}$ Difficult location or poor access (e. g. ileocecal valve, periappendiceal, or anorectal junction); prior failed attempts at resection; non-lifting with submucosal injection; size, morphology, site, and access (SMSA) level 4. ${ }^{7}$ Kudo Vi, Sano IIla. ${ }^{8}$ Kudo Vn, Sano IIIb, narrow-band imaging (NBI) International Colorectal Endoscopic (NICE) classification 3, polyp morphology including ulceration, excavation, deep demarcated depression. ${ }^{9}$ Surgical resection is required because both the lesion and the local draining lymph nodes require excision. ${ }^{10}$ When bleeding risk is high because of antiplatelet or anticoagulant medication or coagulopathy, an individualized approach is justified and prophylactic mechanical hemostasis should be considered.

Each task force proposed statements on their assigned key questions which were discussed and voted on during a guideline meeting in Barcelona in October 2015. In July 2016, a draft prepared by the leaders and coordinating team was sent to all group members. The manuscript was also reviewed by two members of the ESGE Governing Board and sent for further comments to the National Societies and Individual Members. After agreement on a final version, the manuscript was submitted to the journal Endoscopy for publication. All authors agreed on the final revised manuscript.

This Guideline was issued in 2017 and will be considered for review and update in 2022 or sooner if new and relevant evidence becomes available. Any updates to the Guideline in the interim will be noted on the ESGE website: http://www.esge. com/esge-guidelines.html.

\section{Definition, classification, removal, and retrieval of polyps}

\section{RECOMMENDATION}

ESGE recommends that gross morphology of polyps should be described using the Paris classification system and sized in millimeters. (Moderate quality evidence; strong recommendation.) 


\section{RECOMMENDATION}

ESGE recommends that for flat and sessile (Paris II and Is) polyps $\geq 10 \mathrm{~mm}$, termed laterally spreading lesions (LSLs) or laterally spreading tumors (LSTs), surface morphology should be also described as granular or nongranular. (Moderate quality evidence; strong recommendation.)

The Paris classification of superficial neoplastic lesions ( $\vee$ Table 1) [12] updated in 2005 [13], has been adapted from the Kudo classification of early colorectal cancers published in 1993 [14], The Paris classification allows prediction of advanced histology and invasive cancer (type Ilc lesions) [15-17] and it is associated with completeness of endoscopic resection [18]. However, its validity has been questioned as, in a recent study, the interobserver agreement between 7 Western expert endoscopists was only moderate (kappa 0.42) and pairwise agreement, before and after training, was also low at $60 \%$ [19].

LSTs, described in the original Kudo classification, were not included in the Paris classification. LSTs have been further subdivided into granular (homogeneous or nodular-mixed) and nongranular (elevated or pseudodepressed) types because of substantial differences in the risk of invasive cancer [13, 20,21].

The size of both polypoid and nonpolypoid lesions has been shown to be an additional predictive factor for the risk of invasive cancer, allowing a more accurate stratification of the risk according to morphology and size $[12,15-17]$.

\section{RECOMMENDATION}

ESGE recommends that all polyps be resected except for diminutive $(\leq 5 \mathrm{~mm})$ rectal and rectosigmoid polyps that are predicted with high confidence to be hyperplastic. (High quality evidence; strong recommendation.)

\section{RECOMMENDATION}

ESGE recommends retrieval of all resected polyps for histopathological examination. In expert centers, where optical diagnosis may be made with a high degree of confidence, a "resect and discard" strategy may be considered for diminutive polyps. (Moderate quality evidence; strong recommendation.)

Diminutive colonic polyps present a very low risk of cancer $(0-0.6 \%)$ that justifies a "resect and discard" strategy. For hyperplastic polyps located in the rectosigmoid, a "diagnose and leave behind" strategy is appropriate because these harbor an even lower risk of cancer [22]. To guide decisions for diminutive colonic polyps, their histopathology should be assessed during endoscopy in real time with a high accuracy, and the American Society for Gastrointestinal Endoscopy (ASGE) has proposed that, in order to:

1. "Diagnose and leave behind" rectosigmoid diminutive hyperplastic polyps, the technology used should provide
- Table 1 The original Paris classification of superficial neoplastic lesions [12-14].

Pedunculated

Semipedunculated

Sessile, higher than height of closed forceps $(2.5 \mathrm{~mm})$

Slightly elevated, below height of closed forceps $(2.5 \mathrm{~mm})$

Completely flat lesion, does not protrude above mucosal surface

Slightly depressed, lower than mucosa but depth less than $1.2 \mathrm{~mm}$

Excavated/ulcerated, deep ulcer below mucosa below $1.2 \mathrm{~mm}$

a negative predictive value (NPV) $\geq 90 \%$ for adenomatous histopathology;

2. "Resect and discard" diminutive polyps, the technology, when used with high confidence and in combination with the histopathological assessment of polyps $>5 \mathrm{~mm}$, should provide a $\geq 90 \%$ agreement in assignment of post-polypectomy surveillance intervals compared to decisions based on histopathological assessment of all polyps [23].

A meta-analysis showed that the NPVs of narrow band imaging (NBI), flexible spectral imaging color enhancement (FICE; also Fuji Intelligent Chromo Endoscopy) and i-SCAN digital contrast (I-SCAN) for adenomatous polyp histology of small and diminutive colorectal polyps were, for all endoscopists, $91 \%$, $84 \%$, and $80 \%$, respectively; in expert and novice hands, respectively, the NPVs were $93 \%$ and $87 \%$ (NBI), $96 \%$ and $72 \%$ (FICE), and $80 \%$ and $80 \%$ (I-SCAN) [24-26]. Therefore, NBI complies with the abovementioned requirements for both strategies. The important caveats with regard to real-time optical diagnosis concern the endoscopist's expertise in optical biopsy and degree of confidence.

\section{Resection of polyps $<20 \mathrm{~mm}$ in size}

\subsection{Resection of diminutive polyps ( $\leq 5 \mathrm{~mm}$ )}

\section{RECOMMENDATION}

ESGE recommends cold snare polypectomy (CSP) as the preferred technique for removal of diminutive polyps (size $\leq 5 \mathrm{~mm}$ ). This technique has high rates of complete resection, adequate tissue sampling for histology, and low complication rates. (High quality evidence; strong recommendation.)

Studies show that cold snare polypectomy (CSP) is superior to cold biopsy forceps (CBF) for completeness of diminutive polyp resection. In a randomized controlled trial (RCT) that included 117 diminutive polyps sized $<5 \mathrm{~mm}$ in 52 consecutive patients, the rate of histologic eradication was significantly higher in the 
CSP group than in the CBF group ( $93 \%$ vs. $76 \%, P=0.009$ ). Furthermore, the time taken for polypectomy was significantly shorter in the CSP group (14 s vs. 22 s, $P<0.001$ ) [27]. In another RCT that included 145 polyps sized $<7 \mathrm{~mm}$, the complete resection rate for adenomatous polyps was significantly higher in the CSP group compared with the CBF group (96.6\% vs. $82.6 \%$; $P=$ $0.01)$ [28]. CSP also avoids the adverse events associated with thermal electrocautery in hot biopsy forceps (HBF) and hot snare techniques.

\section{RECOMMENDATION}

ESGE recommends against the use of cold biopsy forceps (CBF) excision because of high rates of incomplete resection. In the case of a polyp sized 1-3mm where cold snare polypectomy is technically difficult or not possible, cold biopsy forceps may be used. (Moderate quality evidence; strong recommendation.)

In a prospective study of 52 patients with diminutive polyps that were removed by CBF until no residual polyp tissue was visible, the polypectomy sites were then excised by EMR. The EMR histology showed that only $39 \%$ of the polyps were completely resected using CBF [29]. However, higher complete resection rates have been demonstrated in another study where CBF excision of 86 diminutive polyps was performed with chromoendoscopy until no visible polyp was observed. Each polyp base was then resected using EMR. The complete resection rate was $92 \%$ for all diminutive adenomas (95\% confidence interval $[95 \% \mathrm{Cl}] 85.8-98.8 \%$ ) and $100 \%$ for $1-3-\mathrm{mm}$ adenomas (95\% Cl $81.5-100 \%$ ) [30]. Furthermore, in a retrospective study that evaluated the results from 102 jumbo biopsy forceps polypectomy and 161 standard biopsy forceps polypectomy, onebite CBF polypectomy using either standard or jumbo forceps achieved complete resection for diminutive polyps $<3 \mathrm{~mm}$, though more bites were required with standard forceps for polyps sized 4-5 mm [31].

\section{RECOMMENDATION}

ESGE recommends against the use of hot biopsy forceps (HBF) because of high rates of incomplete resection, inadequate tissue sampling for histopathological examination, and unacceptably high risks of adverse events in comparison with snare excision (deep thermal injury and delayed bleeding). (High quality evidence; strong recommendation.)

In a prospective study involving 62 diminutive rectosigmoid polyps removed via $\mathrm{HBF}, 17 \%$ had persisting viable polyp remnants as shown during follow-up flexible sigmoidoscopy 1-2 weeks later [32]. Another prospective study involving patients with diminutive rectal adenomas found that the rate of remnant adenoma tissue after HBF polypectomy was 10.8\% [33]. The overall diagnostic quality of specimens removed by HBF was shown to be inferior to those removed by jumbo CBF in a prospective study ( $80 \%$ vs. $96 \%$; $P<0.001$ ); furthermore, $92 \%$ of HBF specimens in this study demonstrated cautery damage or crush artifact [34]. In a retrospective study of 1964 diminutive polyps in 753 consecutive colonoscopies, 1525 were removed by HBF, 436 were removed by $\mathrm{CBF}$, and 3 were removed by snare. The risk of significant hemorrhage with $\mathrm{HBF}$ was $0.4 \%$ overall, with the risk highest in the right colon ( $1.3 \%$ in cecum and $1.0 \%$ in the ascending colon) [35]. High rates (32\%-44\%) of transmural colonic injury with HBF were demonstrated in animal studies [36, 37].

\subsection{Resection of small polyps (6-9 mm)}

\section{RECOMMENDATION}

ESGE recommends snare polypectomy for sessile polyps $6-9 \mathrm{~mm}$ in size. ESGE recommends against the use of biopsy forceps for resection of such polyps because of high rates of incomplete resection. (High quality evidence; strong recommendation.)

In an RCT of CSP versus CBF, the rate of residual neoplastic tissue found after polypectomy for polyps sized 5-7 mm was significantly lower in the CSP group compared with the CBF polypectomy group $(6.2 \%$ vs $29.7 \%$; $P=0.13)$ [28]. A similarly low rate of residual neoplastic tissue $(6.8 \%)$ was found in a prospective study that evaluated hot snare polypectomy (HSP) for polyps sized 5-9 mm [38].

\section{RECOMMENDATION}

ESGE suggests CSP for sessile polyps $6-9 \mathrm{~mm}$ in size because of its superior safety profile, although evidence comparing efficacy with HSP is lacking. (Moderate quality evidence; weak recommendation.)

An RCT of HSP vs. CSP for polyps up to $10 \mathrm{~mm}$ in size in 70 patients receiving anticoagulation treatment found that there were significantly higher rates of intraprocedural bleeding (23 $\%$ vs. $5.7 \%, P=0.042$ ) and post-procedural bleeding requiring hemostasis ( $14 \%$ vs. $0 \% ; P=0.027$ ) in the HSP group compared to the CSP group. Complete polyp retrieval rates were equivalent (94\% vs. 93\%) [39]. Another RCT found higher rates of intraprocedural bleeding for CSP vs. HSP (9.1\% vs. $1.0 \%$; $P<$ 0.001 ) for 3-8-mm polyps, although bleeding resolved spontaneously in all cases and therefore was of little clinical significance [40]. In another RCT involving 80 patients with polyps sized $\leq 8 \mathrm{~mm}$, no bleeding requiring hemostasis occurred in the HSP or in the CSP group. However, post-procedure abdominal symptoms were more common in the HSP group $(20.0 \%$ vs. $2.5 \% ; P=0.029)$, and procedure time was significantly shorter with CSP [41]. The advantages of CSP over HSP therefore include lower rates of delayed bleeding, lower frequency of post-polypectomy syndrome, and shorter procedure duration. 


\subsection{Polypectomy of sessile polyps ( $10-19 \mathrm{~mm})$}

RECOMMENDATION

ESGE suggests hot snare polypectomy (HSP) (with or without submucosal injection) for removal of sessile polyps $10-19 \mathrm{~mm}$ in size. In most cases deep thermal injury is a potential risk and thus submucosal injection prior to HSP should be considered. (Low quality evidence; strong recommendation.)

HSP is the predominant technique for removal of polyps of size 10-19 mm, though the data comparing HSP to other techniques in this setting are limited. In a retrospective study of 941 polyps, of the 248 polyps sized $>5 \mathrm{~mm}$ that were removed endoscopically, 191 (77\%) were resected using HSP [42]. For polyps sized 10-19mm, CSP usually cannot achieve "en bloc" resection and the use of biopsy forceps is ineffective for achieving complete resection as well as time-consuming.

In contrast, en bloc resection via HSP is possible, particularly if submucosal injection is used. Submucosal injection can also enhance the safety of HSP for polyps of this size, by reducing the risk of deep thermal injury. The choice of the substance used for submucosal injection used may influence outcomes of HSP for polyps of this size. For example, 196 patients with polyps sized $<20 \mathrm{~mm}$ were randomized to undergo EMR following submucosal injection with either $0.13 \%$ hyaluronic acid or normal saline. Complete resection was achieved in $79.5 \%$ of polyps in the $0.13 \%$ hyaluronic acid group and in $65.6 \%$ of polyps in the normal saline group $(P<0.05)$.

The Complete Adenoma Resection ("CARE") study showed that the rates of incomplete resection with HSP are significantly higher for polyps sized $10-20 \mathrm{~mm}$ compared to smaller polyps (17.3\% vs. $6.8 \% ; P=0.003$ ) [38]. Therefore, colonoscopists must take time to ensure completeness of resection.

\section{RECOMMENDATION}

In certain situations, there may be a role for piecemeal cold snare polypectomy to reduce the risk of deep mural injury, but further studies are needed. (Low quality evidence; weak recommendation.)

In a retrospective study that evaluated piecemeal CSP outcomes in sessile polyps of size $>10 \mathrm{~mm}, 30$ sessile polyps $>10 \mathrm{~mm}$ in size were analyzed, of which 15 were between 10 and $19 \mathrm{~mm}$. All polyps were completely retrieved without any adverse events such as delayed bleeding, post-polypectomy syndrome, or perforation [43]. Of 27 patients who underwent follow-up colonoscopy within 6 months, $80 \%$ did not have residual polypoid tissue at the resection site.

A prospective Argentinian cohort study involving 124 patients, evaluated the safety of CSP where a piecemeal technique was used as required. Of 171 sessile polyps, 43 were sized between 10 and $19 \mathrm{~mm}$. Although there were no subgroup ana- lyses of $10-19-m m$ lesions, no immediate or delayed adverse events such as bleeding or perforation were observed in the overall cohort [44].

Piecemeal CSP has therefore been shown to be safe; however subsequent histological assessment may be less accurate and further prospective studies are required to determine the clinical relevance of this technique and its efficacy for completeness of resection for sessile polyps sized $10-19 \mathrm{~mm}$.

\subsection{Polypectomy of pedunculated lesions}

\section{RECOMMENDATION}

ESGE recommends HSP for pedunculated polyps. To prevent bleeding, in pedunculated colorectal polyps with head $\geq 20 \mathrm{~mm}$ or a stalk $\geq 10 \mathrm{~mm}$ in diameter, ESGE recommends pretreatment of the stalk with injection of dilute adrenaline and/or mechanical hemostasis. (Moderate quality evidence; strong recommendation.)

Most pedunculated lesions are usually easily removed completely by HSP. The main adverse event is post-polypectomy bleeding (PPB). Large pedunculated polyps have an increased risk of PPB because of the presence of a large blood vessel within the stalk [45]. Studies have shown that polyp-related risk factors for PPB include polyp size $>10 \mathrm{~mm}$, stalk diameter $>5 \mathrm{~mm}$, location in the right colon, and the presence of malignancy [4548].

Mechanical hemostasis with endoloops or clips and pharmacological intervention with injection of dilute adrenaline are effective in reducing PPB in pedunculated polyps of size $>10 \mathrm{~mm}$, with the greatest benefit observed in polyps $>20 \mathrm{~mm}[49,50]$. RCTs showed that pretreatment by infiltration of the polyp stalk with 1:10000 adrenaline significantly reduces PPB compared with no intervention $(P<0.05)[49,51]$. However, in another RCT of adrenaline vs. normal saline injection before polypectomy of polyps $>10 \mathrm{~mm}$ in size, the lower rates of bleeding found with adrenaline did not reach statistical significance [52]. Mechanical prophylaxis such as the use of endoloops or endoclips may be superior to adrenaline injections in achieving hemostasis. Two RCTs involving polyps $>20 \mathrm{~mm}$ in size, showed that the use of mechanical devices for pretreatment of the stalk, alone or in combination with adrenaline injection, significantly decreased PPB compared with adrenaline injection alone [53,54]. 


\subsection{Which polyps should be removed by an expert endoscopist in a referral or tertiary center?}

\section{RECOMIMENDATION}

Large $(\geq 20 \mathrm{~mm})$ sessile and laterally spreading or complex polyps, should be removed by an appropriately trained and experienced endoscopist, in an appropriately resourced endoscopy center. (Moderate quality evidence, strong recommendation.)

Large laterally spreading and sessile colorectal lesions $\geq 20 \mathrm{~mm}$ in size (Paris classification 0-Ila, 0-Is, 0-Isp), or lesions located in difficult sites such as the ileocecal valve, appendiceal orifice, and anorectal junction, or located behind haustral folds, should be referred to an expert endoscopist in a tertiary center for removal $[4,55-57]$. In the largest cohort of advanced lesions involving the ileocecal valve (53 patients, median lesion size $35 \mathrm{~mm}$ ), among 47 patients who underwent EMR, complete adenoma clearance was achieved endoscopically in $94 \%$ and ultimately surgery was avoided in $81 \%$ [56]. Although surgery was previously the preferred technique for these "defiant" lesions, endoscopic resection techniques such as EMR offer a safe and effective alternative [58-61]. Recent large EMR cohort studies have demonstrated technical success rates of $>90 \%$ for large laterally spreading and sessile colorectal lesions $[55,57,60]$.

There are few studies that compare differences in outcomes between expert and non-expert colonoscopists. In a retrospective cohort study that compared the outcomes of endoscopic resections of 130 large sessile polyps by 2 specialist and 2 nonspecialist colonoscopists, specialist colonoscopists had a higher success rate ( $75 \%$ vs. $40 \%, P=0.01$ ) [62]. However, a clear definition of an expert endoscopist is not evident in the literature. Similarly, there is no clear definition of what constitutes an appropriately resourced endoscopy center. However, since EMR for large or complex polyps carries substantially greater risk than standard diagnostic colonoscopy, to ensure that patient safety is optimized, the health facility should have the capability to address the range of possible adverse events such as perforation or bleeding. These would include radiology with computed tomography scanning, surgical support, and capability for blood product administration.

\subsection{Polyps requiring other (non-snare) techniques,}

e. g. endoscopic submucosal dissection (ESD) or surgery

\section{RECOMMENDATION}

The majority of colonic and rectal lesions can be effectively removed in a curative way by standard polypectomy and/or by EMR. (Moderate quality evidence; strong recommendation.)
Many studies have shown that snare polypectomy or EMR using submucosal injection followed by en bloc or piecemeal snare resection are suitable for removing the majority of nonmalignant colonic polyps $[4,61,63,64]$. Piecemeal EMR for large polyps is associated with moderate rates of recurrent adenoma ( $16 \%$ in a large prospective study); however, these recurrent lesions are usually diminutive in size and can mostly be easily removed at surveillance colonoscopy, with an ultimately high success rate of $93 \%[4,60]$. The EMR approach is safe, efficient, and cost-effective compared to surgical or other more complex endoscopic alternatives [57,65-69].

\section{RECOMMENDATION}

En bloc resection techniques such as en bloc EMR, ESD, or surgery should be the techniques of choice in cases of suspected superficial invasive carcinoma. (Moderate quality evidence; strong recommendation.)

In cases of suspected superficial invasive carcinoma, endoscopic treatment may be considered curative where the histology shows complete en bloc R0 resection, well-differentiated adenocarcinoma, and $\mathrm{sm} 1$ type ( $<1 \mathrm{~mm}$ submucosal invasion) with no lymphovascular invasion [70]. En bloc resection allows optimal histologic assessment of these factors (see below for additional high risk factors). En bloc EMR is generally limited to lesions $20 \mathrm{~mm}$ in size, with larger lesions usually requiring ESD or surgery for achievement of en bloc resection [71].

\section{RECOMMENDATION}

ESD can be considered for removal of colonic and rectal lesions with high suspicion of superficial submucosal invasion and which otherwise cannot be removed en bloc by standard polypectomy or EMR. (Moderate quality evidence; strong recommendation).

Where the risk of submucosal invasive carcinoma within a lesion is considered high, and en bloc EMR or polypectomy is not achievable, ESD or surgery is recommended.

Surgery is currently the gold standard of treatment with no study showing that ESD has better outcomes than surgery [70]. Surgery has the additional benefit of removing the local lymph nodes in most cases. The main exception may be in the rectum where the complexity of the traditional surgical approach with a higher risk of poor functional outcomes and the risk of abdominoperineal amputation might prompt ESD instead of surgery. A surgical transanal approach may be considered; however this also has limitations including the possibilities of difficult access, suboptimal visualization risking incomplete excision, and postoperative complications [70].

Good outcomes from ESD have been demonstrated in Japanese studies, with disease-specific survival rates of $100 \%$ at the 3 -year and 5-year marks, in a cohort with a median follow-up of 38.7 months (range 12.8 - 104.2 months) [72]. A systematic re- 
view of ESD reported complete resection rates for large colonic polyps of $96 \%$ ( $95 \% \mathrm{Cl} 91 \%-98 \%)$ and a per-lesion summary estimate for R0 resection rate of $88 \%$ (95\%Cl $82 \%-92 \%$ ) [73]. However, ESD of large colonic lesions is technically difficult, time-consuming, mandates multiday hospital stay, and, in Western countries, limited numbers of endoscopists have sufficient experience and expertise to achieve the results described in the East Asian literature.

According to the ESGE ESD Guideline, colorectal ESD may be considered for lesions with high suspicion of limited submucosal invasion based on depressed morphology or irregular surface pattern, or for lesions that otherwise cannot be optimally and radically removed by snare-based techniques [70]. However, further studies comparing ESD to surgery in a Western setting are required to establish the optimal technique. Local expertise will play a major role in determining which approach is used.

\section{RECOMMENDATION}

ESGE recommends that successful EMR be defined endoscopically by the absence of neoplastic tissue at the completion of the procedure after careful inspection of the post-EMR mucosal defect and margin. (Low quality evidence, strong recommendation.)

\section{RECOMMENDATION}

ESGE recommends that endoscopic cure for lesions resected by EMR should be confirmed at surveillance colonoscopy by advanced endoscopic imaging and systematic biopsy. (Low quality evidence; strong recommendation.)

\section{RECOMMENDATION}

ESGE recommends that suspected residual or recurrent adenoma identified at surveillance colonoscopy is snareresected within the same procedure. Where snare resection is not possible, ablation should be performed. (Moderate quality evidence; strong recommendation.)

The goal of EMR is to resect the entire lesion, avoiding recurrence or residual tissue. Ideally the lesion should be resected en bloc, with histologically assessed clear margins (R0 resection). Piecemeal resection prevents the histological assessment of complete excision as the snare excision margins divide the polyp and cannot be distinguished from the in vivo polyp margins.

Complete endoscopic resection refers to complete removal of endoscopically visible polyp either piecemeal [74-76] or en bloc [77]. Inspection of the margins by magnifying endoscopy at the completion of resection has been shown to result in lower rates of recurrence, in a retrospective case-control analysis [78]. There is however no prospective evidence that use of magnification or high definition endoscopy reduces recurrence.
It has been suggested that extending excision margins may reduce recurrence after $\operatorname{EMR}[74,79,80]$; however a prospective observational cohort study of $>800$ patients failed to show any reduction in recurrence at scheduled surveillance at 4-6 months [81].

Snare resection should be prioritized at the initial resection to remove all polyp, or as much polyp as possible [82]. The detection of residual or recurrent polyp at surveillance colonoscopy is of high importance. Recurrence occurs in 15\%-20\% of EMRs [83]. There are few studies that have examined the accuracy of endoscopic imaging for the prediction of histological recurrence. Recently a large prospective study using a simple standardized imaging protocol with high definition white light endoscopy followed by NBI showed an NPV for recurrence of $98.6 \%(95 \% \mathrm{Cl} 95.1 \%-99.8 \%)$. The use of $\mathrm{NBI}$ in addition to high definition white light endoscopy improved sensitivity for recurrence from $67 \%$ to $93 \%$, the difference mainly due to detection of flat recurrence [84].

Residual or recurrent polyp tissue detected at endoscopic surveillance can be effectively treated [60]. Snare resection provides superior outcomes to other modalities [60]. For areas not amenable to snare resection, multiple endoscopic modalities have been described in the past to destroy residual polyp, although none have been demonstrated in a systematic way to reduce recurrence in conjunction with contemporary EMR techniques [85]. Hot avulsion is a technique that can be applied to small areas of non-lifting polyp and was effective in a small prospective study $[86,87]$. Alternative strategies for non-lifting polyp including cold avulsion in conjunction with thermal ablation are being investigated. Recurrent lesions with substantial fibrosis may be suitable for ESD resection. The en bloc resection rate in Japanese studies is lower for salvage ESD than for naive lesions [88]. Underwater EMR has been examined in a small study as an alternative salvage therapy, with en bloc resection rates in this setting of $47.2 \%$ vs. $15.9 \%$ for standard EMR [75].

\section{RECOMMENDATION}

ESGE recommends the use of advanced endoscopic imaging to identify the potential presence of superficial submucosal invasion. (Moderate quality evidence; strong recommendation.)

Advanced imaging techniques such as narrow band imaging (NBI) and magnifying chromoendoscopy (MCE) have been shown to improve the identification of morphological features suggestive of submucosal invasion, such as irregular or absent surface vascular patterns [89-91]. NBI studies showed that the Sano capillary pattern IIIB, Hiroshima C3, and NBI International Colorectal Endoscopic Classification (NICE) 3 are highly indicative of deep invasion [92-95]. MCE studies demonstrated that Kudo pit pattern $\mathrm{Vn}$ is associated with a high likelihood of deep submucosal invasion $[96,97]$. Sano IIIA, and Kudo pit pattern Vi are predictive of superficial submucosal invasive carcinoma, and can therefore identify patients who will benefit from en bloc resection. 


\section{RECOMMENDATION}

ESGE suggests that when advanced imaging is not available, standard chromoendoscopy may be beneficial. (Moderate quality evidence; strong recommendation.)

Polyp morphology such as ulceration, excavation, deep demarcated depression, Paris classification II-c and Ila $+\mathrm{c}$, nongranularity, mucosal friability, fold convergence and Kudo pit pattern $\mathrm{V}$ are associated with submucosal invasive carcinoma [4, 98-101]. Many of these features may be visible with standard or high definition white light inspection. Even when magnification technology is not available, standard chromoendoscopy may be useful in further enhancing the identification of these features.

\section{RECOMMENDATION}

ESGE recommends that polyps with advanced endoscopic imaging characteristics of deep submucosal invasion should not be considered for endoscopic treatment and should be referred for surgery. (Moderate quality evidence; strong recommendation.)

Polyps demonstrating endoscopic signs of deep submucosal invasion are at high risk of lymphovascular invasion and lymph node metastasis [102-104]. In a meta-analysis of 23 cohort studies involving 4510 patients, a significantly higher risk of lymph node metastasis was associated with a depth of submucosal invasion $>1 \mathrm{~mm}$ compared with superficial invasion (odds ratio [OR 3.87], $95 \% \mathrm{Cl} 1.50-10.00 ; P=0.005)$. Lymphovascular invasion (OR 4.81, $95 \% \mathrm{Cl} 3.14-7.37$; $P<0.001)$, poorly differentiated tumors (OR 5.60, $95 \% \mathrm{Cl} 2.90-10.82 ; P<0.001)$, and tumor budding (OR 7.74, $95 \% \mathrm{Cl} 4.47$-13.39; $P<0.001$ ) were significantly associated with lymph node metastasis [104]. Therefore, in addition to excision of the lesion, the local draining lymph nodes must also be removed when deep submucosal invasion is suspected or proven, which can only be achieved by surgery.

\section{RECOMMENDATION}

ESGE recommends that polyps without characteristics of deep submucosal invasion should not be referred for surgery without consultation with an expert endoscopy center for evaluation for polypectomy/EMR. (Low quality evidence, strong recommendation.)

Polyps without characteristics of deep submucosal invasion, have a high likelihood of being successfully removed endoscopically at expert centers, and these patients should be offered a consultation to discuss endoscopic management before proceeding to surgery [105]. In a recent EMR study, 36 patients with 38 large or complex polyps without biopsy-proven cancer were redirected to consultation with an EMR expert by a colorectal surgeon who received the original referrals: $79 \%$ of lesions could be successfully treated endoscopically and surgery was avoided in $71 \%$ of the patients [106].

\subsection{Colonic tattooing: which lesions should be tattooed, and what is the best technique and location for tattoo placement?}

\section{RECOMMENDATION}

ESGE recommends that lesions that may need to be located at future endoscopic or surgical procedures should be tattooed during colonoscopy. (Low quality evidence, strong recommendation.)

Colonoscopic tattooing is performed to enable future identification, at colonoscopy or surgery, of malignant lesions (proven or suspected), polypectomy, EMR, or ESD sites, difficult-to-detect polyps, or dysplastic areas. All such lesions, other than those definitely located in the cecum, adjacent to the ileocecal valve, or in the low rectum, should be tattooed.

\section{RECOMMENDATION}

ESGE recommends sterile carbon particle suspension as the preferred tattoo agent. (Low quality evidence, strong recommendation.)

A variety of substances were previously used for endoscopic tattooing, including india ink, methylene blue, indigo carmine, and indocyanine green [107]. These were limited by difficulties including lack of permanence, infection resulting from impurities, or complex preparation. A sterile and biocompatible prepackaged suspension containing highly purified and very fine carbon particles (Spot; GI Supply, Camp Hill, Pennsylvania, USA) has been developed for endoscopic tattooing and this has enhanced the accessibility, ease of use, and safety of the procedure [108].

\section{RECOMMENDATION}

ESGE recommends the formation of a saline bleb in the submucosal layer of the colon prior to tattoo injection. (Low quality evidence; strong recommendation.)

Sterile carbon particle suspension is not biologically inert and has been associated with clinically significant complications [109]. These include reported cases of peritonitis resulting from transmural injection $[107,109,110]$ and submucosal fibrosis that makes EMR or ESD difficult and hazardous and has contributed to endoscopic perforation [109,111]. Furthermore, poor injection technique has resulted in failure to identify the tattoo at surgery [110]. These risks can be reduced by choosing an appropriate location for tattooing [109, 112, 113], 
and by the use of the saline bleb injection method $[110,114]$. The saline bleb injection method involves performing a normal saline injection initially to find the submucosal plane and ensure that a submucosal bleb is safely created. Once the submucosal bleb has been formed, the normal saline syringe is replaced with the tattoo syringe, and injection is recommenced. This ensures tattoo injection into the submucosal plane, avoiding transmural injection that may cause localized peritonitis, and is also associated with more accurate surgical location compared with standard tattooing $[110,114]$.

\section{RECOMMENDATION}

ESGE recommends that tattoos be placed $\geq 3 \mathrm{~cm}$ anatomically distal (anal side) to the lesion, with 2 or 3 separate injections being made at this level on opposite sides of the lumen, to increase the likelihood of detection. Endoscopic and surgical team members should agree on a standardized location of tattoo injection at their institution. The details of tattoo injection should be clearly text- and photo-documented in the endoscopy report, using unambiguous terminology. (Low quality evidence; strong recommendation.)

The recommended tattoo location of $2-3 \mathrm{~cm}$ distal (on the anal side) to the lesion $[109,112,113]$ is at an adequate distance to limit the likelihood of inadvertent spread beneath the lesion and also avoid inadvertent injection through the lesion that may cause needle-track seeding $[109,112,115,116]$. The carbon particles can spread a significant and often unexpected distance within the submucosal plane as the submucosal bleb flattens and expands laterally, potentially spreading underneath the lesion and inducing submucosal fibrosis, which can limit subsequent endoscopic therapy.

It is also recommended that 2 or 3 separate injections should be performed at this level of $2-3 \mathrm{~cm}$ distal (anal side) to the lesion. One injection should be in line with the lesion, and one should be on the opposite aspect of the lumen. This may increase the likelihood that the tattoo will be seen at future endoscopy or surgery. A tattoo volume of at least $1.0-1.5 \mathrm{~mL}$ at each injection site has been recommended $[109,110]$. A volume of $3 \mathrm{~mL}$ of sterile carbon particle suspension has also been suggested if one is confident that the needle-tip is located within the submucosal plane [110].

\section{Endoscopic mucosal resection (EMR) for sessile laterally spreading lesions $\geq 20 \mathrm{~mm}$ in size}

EMR involves injection of a solution into the submucosal space to separate a mucosal lesion from the underlying muscularis propria. The lesion can then be resected by snare electrosurgery. The submucosal cushion theoretically reduces the risk of thermal or mechanical injury to the underlying muscularis propria.

Sessile and flat colorectal laterally spreading lesions (LSLs) (or laterally spreading tumors [LSTs]) $\geq 20 \mathrm{~mm}$ in size require advanced techniques for resection. Large prospective studies have demonstrated that EMR is safe and efficacious $[4,63$, 117]. There is now a growing evidence base for several key technical aspects of the procedure, aimed at improving complete resection rates, reducing recurrence, and lowering rates of complications including perforation, bleeding, and post-procedural pain. Advanced endoscopic resection requires a patient- and lesion-centered approach, where the endoscopist must carefully appraise the risks of submucosal invasive cancer, the risks and benefits of resection techniques, and the co-morbidities of the patient. Although EMR is effective and safe for the vast majority of sessile flat colorectal LSLs without imaging features suggestive of invasive disease, surgical resection or endoscopic submucosal dissection (ESD) may be appropriate alternatives for higher risk lesions.

\section{RECOMMENDATION}

ESGE recommends careful lesion assessment prior to EMR to identify features suggestive of poor outcome. Features associated with incomplete resection or recurrence include lesion size $>40 \mathrm{~mm}$, ileocecal valve location, prior failed attempts at resection, and size, morphology, site, and access (SMSA) level 4. (Moderate quality evidence; strong recommendation.)

Large polyp size as a predictor of recurrence or failed endoscopic therapy has been demonstrated in several studies $[4,55$, $61,118]$. Prior attempts at resection have been shown to be associated with failed subsequent endoscopic resection. Nonlifting due to previous intervention was associated with failed resection in the large prospective Australian Colonic EMR (ACE) study (OR 3.75) [60] and a US study identified prior resection attempts as a risk factor for failure of complete resection (OR 0.081; $P<0.001$ ), or recurrence (OR 18.8; $P<0.001$ ) [119]. Lesion location may be associated with incomplete resection. Lesions at the ileocecal valve were associated with failed resection in the ACE study (OR 2.61) and, although good endoscopic outcomes can be achieved in this location, involvement of the ileum or both the superior and inferior lips of the valve was associated with recurrence [120]. Other locations that may prove challenging include the appendiceal orifice and anorectal junction [121]. Methods to overcome these challenges have been described and prospectively studied [120,121]. Difficult access was associated with failed endoscopic resection in the ACE study [4] (OR 2.17), and locations behind folds, in a constrained sigmoid colon, or in peridiverticular locations may also reduce complete resection rates.

Post-EMR bleeding occurs in $5 \%-7 \%$ following resection of lesions $\geq 20 \mathrm{~mm}[122,123]$. Identified risk factors for bleeding include proximal colon location $[48,122,124]$ and increasing lesion size, especially $\geq 40 \mathrm{~mm}[77,125]$. The combined effects of size and location in the English Bowel Cancer Screening Programmme identified a predicted risk of bleeding of 1 in 8 [125]. Perforation is an uncommon event, and meta-analyses show pooled estimates of $1.4 \%-1.5 \%[123,126]$. Few studies have identified independent risk factors for perforation as analyses 
are prone to error when there are few outcomes. In large series examining standard polypectomy, "adverse event" outcomes (combining bleeding and perforation) have identified endoscopist inexperience and increasing lesion size as risk factors [127-130].

A simple method for stratifying lesion complexity, based on the size, morphology, site, and access (SMSA), has been developed by a working group of UK experts [131]. This stratifies polyps into four levels of difficulty with level 1 being the easiest and level 4 being very difficult to resect. Validation of this system in 220 lesions $\geq 20 \mathrm{~mm}$ in size demonstrated higher complication rates $(8.6 \%$ vs. $0 \%, P=0.007)$ and lower clearance rates $(87.5 \%$ vs. $97.5 \%, P=0.009)$ for SMSA level 4 polyps as compared to SMSA level 2 and 3 [55]. The classification is user-friendly, takes account of most described risk predictors and may be valuable for the assessment of large and complex polyps.

Lesions that have high risk features suggesting poor outcomes may be more safely and effectively handled at a high volume tertiary referral centre. The endoscopist must be confident that the resources available to them (staff, equipment, time, and endoscopic skill) are sufficient to remove the entire lesion safely and manage potential adverse events. If not, referral to a tertiary care center should be strongly considered [57,61].

\section{RECOMMENDATION}

ESGE recommends that the goals of EMR are to achieve a completely snare-resected lesion in the safest minimum number of pieces, with adequate margins, and without need for adjunctive ablative techniques. (Low quality evidence; strong recommendation.)

Effective resection technique relies on multiple interdependent factors, but is difficult to study objectively as it requires the intersection of a number of endoscopic skills, including optical diagnosis, endoscope shaft and tip control, injection technique, snare selection and manipulation, visual and haptic feedback, and judgment. Several sources including technical reviews and expert opinion are available to guide technique [78, 82,132,133].

Complete and safe excision often requires an adaptable approach to the lesion and the techniques employed may vary slightly between operators. Factors associated with the lowest recurrence risk are complete snare resection, en bloc or oligopiecemeal excision, and the absence of adjunctive thermal ablative techniques.

\section{RECOMMENDATION}

ESGE suggests the use of submucosal injectates for EMR that are more viscous than normal saline and whose safety has been proven, including succinylated gelatin, hydroxyethyl starch, or glycerol, since their use is associated with superior technical outcomes and reduced procedural time. (High quality evidence; weak recommendation.)
RECOMMENDATION

ESGE recommends that a biologically inert blue dye such as indigo carmine should be incorporated into the submucosal injection solution to facilitate identification of fluid cushion extent, lesion margins, and deep mural injury. (Moderate quality evidence; strong recommendation.)

The ideal submucosal injectate should provide a sustained lift, facilitate en bloc or oligo-piecemeal resection, be inexpensive, widely available, and have few adverse effects [134]. The traditional EMR submucosal injectate is normal saline; however several other solutions have been investigated $[135,136]$.

Succinylated gelatin (Gelofusine; B. Braun, Crissier, Switzerland), has been compared to normal saline in an Australian double-blind RCT of EMR for lesions $\geq 20 \mathrm{~mm}$ ( $n=80$ patients). Succinylated gelatin results in fewer snare resections per lesion (3.0 vs. $5.5, P=0.028$ ) and shorter procedure duration (12.0 min vs. $24.5 \mathrm{~min}, P=0.006$ ) [137]. Succinylated gelatin is not universally available and there is a theoretical risk of an allergic reaction to bovine protein; however it has been used in a large multicenter cohort of over 1000 patients without complications [60].

Hydroxyethyl starch (Voluven; Fresenius Kabi Ltd, Runcorn, UK) has been shown to improve mucosal lift time, reducing the need for additional injections in a randomized controlled study [138]. Hyaluronic acid has also been demonstrated to improve complete resection and prolong mucosal elevation in several animal and human studies [139-142]. It is commonly used in ESD procedures [143]; however it is expensive [144] and not widely available, which has limited its uptake. In addition, murine models have suggested a potential for the stimulation of growth of residual adenoma [145].

Glycerol is a hypertonic solution consisting of $10 \%$ glycerin and $5 \%$ fructose in normal saline. In a retrospective case - control study, en bloc resection rates were improved with use of glycerol compared with normal saline [146]. Glycerol is widely available and inexpensive in Japan, but is not used extensively elsewhere [144].

Other hypertonic crystalloid solutions have been investigated in human and animal studies. Hydroxypropyl methyl cellulose sustains mucosal lift in animal studies [147] and is non-inferior to normal saline in humans [148-150]. Dextrose solutions produce a sustained mucosal lift [151 - 153]; however tissue damage has been reported in animal studies, particularly with concentrations over $20 \%$ [154]. In a double-blind, randomized human EMR study, post-polypectomy syndrome was significantly more likely in patients treated with submucosal injection of $50 \%$ dextrose with adrenaline compared with normal saline with adrenaline [151]. Similar effects have been noted with hypertonic saline [154].

Fibrinogen and blood injectates have also been used for EMR in animal models; however there are concerns regarding pathogen contamination and practicality $[155,156]$. 
Incorporation of a biologically inert dye into the submucosal injectate facilitates identification of fluid cushion extent, lesion margins, and deep mural injury $[5,135]$. Topical application of injectate with a chromic agent to resection defects may assist in the delineation of deep injury [157].

\section{RECOMMENDATION}

ESGE suggests that en bloc EMR should be limited to lesions $\leq 20 \mathrm{~mm}$ in the colon and $\leq 25 \mathrm{~mm}$ in the rectum. (Low quality evidence, weak recommendation.)

En bloc resection by EMR for lesions $\geq 20 \mathrm{~mm}$ is reported in $16 \%-48 \%$ of lesions $[60,61,79,158]$. It is associated with lower recurrence rates than piecemeal resection in both EMR and ESD studies $[60,143]$. No studies have defined a cutoff point for size where en bloc resection is unsafe, so it remains a decision that is based on lesion morphology and location. The factors that limit en bloc resection by EMR are polyp size, location, EMR technique, and the experience of the endoscopist [159]. Finally however the primary driver must be consideration of safety. For flat and sessile colonic lesions the maximum size that can be reliably excised en bloc by EMR is $15-20 \mathrm{~mm}$ proximal to the splenic flexure where the risk of perforation is high$\mathrm{er}$, and $20-25 \mathrm{~mm}$ in the sigmoid and rectum [160]. If en bloc resection is not possible, the lesion should be removed in as few pieces as possible [160].

Circumferential incision of lesions using ESD techniques (cEMR, CSI-EMR, or EMR-precut) may allow extension of the size limits while mitigating perforation risk [79, 80, 161]. Use of special devices such as dual-loop snares may also increase the rate of en bloc resection for lesions $\geq 20 \mathrm{~mm}$ to $64 \%$ [162]. Underwater EMR has demonstrated en bloc resection rates of $55 \%$ for colorectal lesions of 20-40 mm [163].

\section{RECOMMENDATION}

ESGE recommends complete snare resection during EMR, because adjunctive thermal ablative techniques (e. g. argon plasma coagulation [APC]) are not as effective and are associated with higher adenoma recurrence. (Moderate quality evidence; strong recommendation.)

\section{RECOMMENDATION}

ESGE suggests that where complete snare excision cannot be achieved, the optimal method for adjunctive removal of residual adenoma requires further study. (Low quality evidence; weak recommendation.)

\section{RECOMMENDATION}

ESGE suggests that where complete snare excision EMR has been achieved, the role of adjuvant thermal ablation of the EMR resection margins to prevent recurrence requires further study. (Low quality evidence; weak recommendation.)

Ablation at the margins of the EMR defect may have two roles: as an "adjunct" treatment, where residual tissue not amenable to snare resection is ablated, or as an "adjuvant" treatment, where ablation is applied to clean defect margins in an effort to reduce recurrence.

Two small RCTs have demonstrated conflicting results for adjuvant APC, with one showing a significantly reduced rate of recurrence with APC application $[164,165]$ and the other showing no effect [141]. There are no contemporary high quality studies examining adjuvant thermal ablation techniques.

Small low quality prospective cohort studies have examined adjunctive thermal ablation with APC; however results have been inconclusive $[85,166]$.

The prospective ACE study ( $n=479$ patients, 514 lesions, mean size $35.6 \mathrm{~mm}$ ) aimed for a treatment goal of complete snare resection. Where this was not achieved, remnant tissue was ablated by APC or snare-tip soft coagulation. Independent predictors of lesion recurrence included lesion size $>40 \mathrm{~mm}$ (OR 4.37) and use of APC (OR 3.51) [4]. The role of adjuvant thermal ablation of the post-EMR margin, where no endoscopically visible adenoma remains despite meticulous inspection, requires further rigorous evaluation.

\section{RECOMMENDATION}

ESGE recommends that when a lesion appears suitable for EMR, but does not lift with submucosal injection, referral should be made to an expert endoscopist in a tertiary center. (Moderate quality evidence, strong recommendation.)

Obliteration of the submucosal space that precludes lesion elevation with submucosal injection may be caused by early colorectal cancer, and with the associated desmoplastic response the mucosal layer can be tethered to the underlying muscularis propria. Fibrosis related to polyp prolapse, prior resection attempts $[119,167]$, or as a reaction to submucosal injection of tattoo particles [109] may also cause this. Non-lifting is evident when submucosal injection fails to elevate the lesion, but lifts the surrounding mucosa creating a canyoning effect. Infiltration into the submucosal space may not be possible, resulting in a jet of fluid exiting the lesion under pressure.

Non-lifting was first described in 1994 in a prospective series [168] and was strongly associated with submucosal invasion (SMI). It was subsequently shown that superficial SMI (SM1, involvement of the submucosa $<1000 \mu \mathrm{m}$; SM2, involvement of the submucosa $<2000 \mu \mathrm{m}$ ) was not as strongly associated with 
non-lifting as deep SMI (SM3,>2000 $\mu \mathrm{m}$ involved), as the underlying preserved submucosa may still expand [169]. Other studies have re-demonstrated this association of non-lifting with SM3 disease $[170,171]$. Kobayashi et al. showed that endoscopic assessment with chromoendoscopy was superior to non-lifting for predicting submucosal invasion [171], so careful endoscopic assessment of surface pattern and morphology is considered to be the optimal method of determining invasion, preferably using magnification endoscopy and digital or topical chromoendoscopy [172].

Endoscopic resection by a typical inject and resect method may be ineffective or incomplete, requiring the use of adjunctive thermal ablation [173] or avulsion techniques (hot or cold) $[86,87]$ to remove all visible polyp. All visible adenoma should be excised before ablation is considered. Good outcomes have been reported at high volume tertiary referral centers $[4,61$, 119] and in series using ESD techniques [88].

\section{RECOMMENDATION}

ESGE recommends that all EMR specimens be retrieved for histological evaluation. (Moderate quality evidence; strong recommendation.)

Although the Roth retrieval net device is usually used to retrieve polyp fragments after large or piecemeal polypectomy without compromising pathologic evaluation [174], systematic literature search yields no evidence-based data on this point regarding LSLs.

\section{Equipment considerations for polypectomy and EMR}

\subsection{Type of current}

\section{RECOMMENDATION}

ESGE suggests the use of a microprocessor-controlled electrocautery generator for polypectomy. (Low quality evidence; weak recommendation.)

Electrosurgical units convert energy from high frequency currents (between $300 \mathrm{kHz}$ and $1 \mathrm{MHz}$ ) into heat. When high frequency electrosurgical current flows from a snare wire through tissue, the high density current at the point of contact results in a sharp rise in tissue temperature.

Cutting currents are produced at temperatures greater than $100^{\circ} \mathrm{C}$, which leads to boiling of cellular water and subsequent cellular rupture.

Coagulation currents are produced at temperatures of $70-$ $100{ }^{\circ} \mathrm{C}$. This leads to dehydration and contracting of cells, without rupture.

With use of blended currents, the ratio of cells cut to those coagulated can be varied.
For polypectomy, it is recommended that automated microprocessor technologies are used that enable controlled tissue cutting by providing an appropriate blend of cutting and coagulation currents. This provides enough coagulation current to maximize the hemostatic effect and minimize the risk of perforation $[175,176]$.

\section{RECOMMENDATION}

ESGE recommends against using low power coagulation current for EMR because of the increased risk of post-procedural bleeding. (Low quality evidence; strong recommendation.)

Use of diathermy current for polypectomy varies according to individual practitioner. A North American survey [177] of polypectomy practice of nearly 200 endoscopists demonstrated that $46 \%$ favour a blended current, $46 \%$ a pure coagulation current, $3 \%$ a pure cutting current, and $4 \%$ used a variety. More recently an Israeli survey [178] showed similar results, with $42 \%$ favouring pure coagulation and $38 \%$ blended current with a higher use of pure cutting current at $20 \%$. Pure cutting current is best avoided because of the risk of immediate post-polypectomy bleeding [47].

Pure coagulation current is popular amongst endoscopists because of its efficient hemostatic properties; however, it is well recognised that prolonged use of coagulation results in deep thermal tissue injury [179], increasing the risk of perforation, particularly in the right colon. A large study of nearly 1500 polypectomies [180] retrospectively compared blended versus pure coagulation current. Overall complication rates were the same between the two groups. However, there was a statistically significant difference in the timing of bleeding: for blended current within 12 hours, and for pure coagulation current within 2-8 days. Pure coagulation current when applied for EMR of flat lesions especially in the right colon is likely to increase the risk of perforation and is best avoided.

Use of an electrosurgical current not controlled by a microprocessor was associated with clinically significant post-endoscopic bleeding (OR 2.03; $P=0.038)$ [122].

\section{RECOMMENDATION}

ESGE recommends against using pure cutting current for pedunculated polypectomy because of an increased risk of intraprocedural bleeding. (Low quality evidence; strong recommendation.)

Pure cutting current is not recommended for polypectomy because of the increased associated risk of intraprocedural bleeding. A large, multicenter Korean study [47], with a total of 9336 polypectomies, found that cutting current and inadvertent cold polypectomy had the highest ORs for immediate postpolypectomy bleeding, at $6.95(95 \% \mathrm{Cl} 4.42-10.94)$ and 7.15 , $(95 \% \mathrm{Cl} 3.13-16.36)$, respectively. A large retrospective study 
[180] also found that immediate post-polypectomy bleeding was observed more with blended current and delayed post-polypectomy bleeding occurred more frequently with coagulation current.

A retrospective review encompassing 4735 polypectomies performed using pure cutting current found that bleeding occurred in $3.1 \%$ of the patients. In this study, hemoclips were prophylactically placed at the endoscopist's discretion and a significant proportion of patients (12\%) received them [181].

Resection of pedunculated polyp is achieved by cutting the pedicle. This minimizes the risk of perforation as the pedicle is away from the colon wall, but the pedicle could contain a thick vessel. Inadequate coagulation of this vessel can result in catastrophic bleeds. Therefore, it may be logical to use pure coagulation current for resection of pedunculated polyps. However, there are no high level data comparing pure coagulation current to microprocessor controlled current for pedunculated polyps.

\subsection{Carbon dioxide $\left(\mathrm{CO}_{2}\right)$ insufflation}

RECOMMENDATION

ESGE suggests the use of carbon dioxide $\left(\mathrm{CO}_{2}\right)$ insufflation during colonoscopy and polypectomy. (Low quality evidence, strong recommendation.)

Carbon dioxide $\left(\mathrm{CO}_{2}\right)$ is absorbed $>100$ times more quickly than air and can reduce patient discomfort during and after the procedure. A meta-analysis of 9 RCTs involving 1577 patients showed fewer patients with intraprocedural abdominal pain in the $\mathrm{CO}_{2}$ group (relative risk [RR] $0.77,95 \% \mathrm{Cl} 0.62-0.96$ ). Use of $\mathrm{CO}_{2}$ also reduced immediate post-procedural pain at 1 hour (RR $0.26,95 \% \mathrm{Cl} 0.16-0.43$ ) and 6 hours (RR 0.36, $0.20-0.64$ ), and post-procedure discomfort at 24 hours (RR 0.53, 0.31 0.91 ) though there was no significant difference in cecal intubation rate [182].

An RCT assessing the impact of $\mathrm{CO}_{2}$ insufflation on toilet use after screening colonoscopy showed that at 2 hours post-procedure, $30 \%$ in the $\mathrm{CO}_{2}$ group had used the toilet at least once, compared to $83 \%$ in the air insufflation group $(P<0.001)$. The average duration of each toilet visit was also significantly shorter in the $\mathrm{CO}_{2}$ group [183].

RECOMMENDATION

ESGE recommends the use of $\mathrm{CO}_{2}$ insufflation for EMR. (Moderate quality evidence; strong recommendation.)

EMR is associated with a higher risk of perforation than standard colonoscopy.

Performing EMR also lengthens the procedure time and the duration of gas insufflation. A prospective cohort study of patients undergoing EMR of large colonic lesions demonstrated a $62 \%$ reduction in the number of post-procedure admissions when $\mathrm{CO}_{2}$ insufflation was used compared to air (8.9\% vs. $3.4 \%$, $P=0.01$ ) [184]. $\mathrm{CO}_{2}$ insufflation is advisable in case EMR leads to perforation, as use of $\mathrm{CO}_{2}$ will allow clinicians more time to manage the perforation as compared to use of air which can lead to rapid abdominal distension, tension pneumoperitoneum, gas tracking, pain, and hemodynamic compromise.

\subsection{Type of snare}

Limited data exist that compare the roles of different types of snares. We recommend that clinicians use snares with which they are familiar and whose performance characteristics are known. Snare size should be appropriately selected depending on the size and morphology of the polyp. Snares come in different shapes (circular, oval, hexagonal, etc.) but no clear benefit of one shape over the other has been demonstrated. Structurally, snares are either monofilament or polyfilament. The potential advantage of monofilament snares is that the snare wire is thin $(<0.4 \mathrm{~mm})$, so current density is greater, tissue transection swifter, and unintentional diathermic injury to the colonic wall less likely. The potential advantage of polyfilament snares are that the wire is thicker $(0.4 \mathrm{~mm}-0.5 \mathrm{~mm})$ and thus they may better grip the mucosal surface (depending on what other performance enhancements have been included in the wire design) enabling more effective capture of flat polyps. However, these differences in performance have not been proven and ESGE strongly recommends further research in this field.

\subsection{Fluid pump}

\section{RECOMMENDATION}

ESGE suggests the use of a fluid jet pump to enable efficient irrigation of the colonic mucosa and polypectomy sites and management of bleeding. (Low quality evidence; weak recommendation.)

Use of a fluid jet can be very effective in locating the exact point of bleeding during polypectomy or EMR. This fluid may be water or normal saline. If the fluid jet is delivered via a separate dedicated channel in the endoscope (as in most modern endoscopes) then the working channel of the endoscope is available for the endoscopist to employ hemostatic devices whilst the fluid jet is delineating the precise bleeding point.

\section{Polypectomy-associated adverse events: definitions and management}

\subsection{Bleeding}

Consensus on the definition of post-polypectomy bleeding is lacking. Definitions vary throughout the literature. For the purposes of these guidelines, two terms were used: intraprocedural bleeding and post-procedural bleeding. These were defined as follows:

- Intraprocedural bleeding (IPB) is bleeding occurring during the procedure that persists for more than 60 seconds or requires endoscopic intervention. 
- Post-procedural bleeding (PPB) is bleeding occurring after the procedure, up to 30 days post-polypectomy, that results in an unplanned medical presentation such as emergency department visit, hospitalization, or re-intervention (repeat endoscopy, angiography, or surgery).

\section{RECOMMENDATION}

For intraprocedural bleeding, ESGE recommends endoscopic coagulation (snare-tip soft coagulation or coagulating forceps) or mechanical therapy, with or without the combined use of dilute adrenaline injection. (Low quality evidence; strong recommendation.)

IPB occurs in $2.8 \%$ of patients undergoing standard polypectomy [49] and in $11.3 \%$ of patients with lesions $\geq 20 \mathrm{~mm}$ treated with endoscopic mucosal resection (EMR) [122] and it is rarely serious. Management of IPB can be achieved with endoclips, coagulation forceps, and snare-tip soft coagulation. Snare-tip soft coagulation has been shown to be an effective method of IPB control [185]. Coagulating forceps are reserved for more severe cases [82,132]. Vigorous irrigation, preferably by using a water pump, improves visualization and may aid cessation of bleeding originating from small vessels [82,132]. Adrenaline injection (1:10000 or 1:20000 dilution with saline) may be used to gain initial control of active bleeding but should always be used in combination with a second mechanical or thermal hemostatic method.

IPB that occurs after removal of a pedunculated polyp, can be managed by placing a clip or an endoloop. In cases of immediate massive IPB, the snare may be used to resnare the remaining stalk with temporary control of bleeding providing time for subsequent clip or endoloop application. Where a significant volume of blood is pooling and overlying the bleeding point, this can make it difficult to identify and treat the precise bleeding point. In such a case, rolling the patient so that the bleeding point is away from the gravity-dependent position will enable the bleeding point to be clearly visualized and treated. The over-the-scope clip (OTSC; Ovesco Endoscopy, Tuebingen, Germany) has also been shown to be effective for control of IPB that is refractory to other endoscopic modalities [186]. The advantage of using this device is that it can grasp a much wider area and larger volume of tissue than the through-thescope endoclips; however withdrawal of the endoscope to load the device is necessary, further delaying hemostasis.

\section{RECOMMENDATION}

ESGE does not recommend routine endoscopic clip closure or other methods of prophylaxis to prevent delayed bleeding for sessile polyps. (Moderate quality evidence; weak recommendation.)
An RCT, has reported that prophylactic clip application does not decrease PPB after EMR [187]. However, in an uncontrolled retrospective study of 524 unselected polyps $\geq 20 \mathrm{~mm}$ in size, prophylactic clipping of resection sites was found to reduce the risk of PPB [188]. More RCTs on this subject are required. Moreover, in another RCT, prophylactic endoscopic coagulation of nonbleeding visible vessels within the mucosal defect after wide-field EMR, using coagulation forceps at fixed low power, did not reduce the incidence of PPB [189].

\section{RECOMMENDATION}

ESGE suggests that there may be a role for mechanical prophylaxis (e.g. clip closure of the mucosal defect) in certain high risk cases after polypectomy or EMR. This decision must be individualized based on the patient's risk factors. (Low quality evidence; weak recommendation.)

Factors associated with the incidence of post-procedural bleeding (PPB) are either related to polyp characteristics such as size, morphology, and location of the polyp, or to the patient's health status such as age $>65$ years, the presence of hypertension, renal disease, and use of anticoagulant. PPB complicates $6 \%-7 \%$ of wide-field EMRs [122]. Data from EMR of sessile colorectal polyps $\geq 20 \mathrm{~mm}$ in size showed, that PPB was associated with proximal location, use of an electrosurgical current not controlled by a microprocessor, occurrence of IPB, and aspirin use $[122,124]$. In the Munich Polypectomy Study, polyp size and the proximal location of the polyp were risk factors for adverse events such as PPB [128]. A meta-analysis has shown that the risk of PPB was significantly increased for patients using clopidogrel [190]. A cost-efficacy decision analysis of prophylactic clip placement after endoscopic removal of large polyps has shown that this strategy appears to be cost-effective for patients who receive antiplatelet or anticoagulation therapy [191]. Prophylactic endoscopic clipping may thus be considered for preventing delayed bleeding in patients receiving antiplatelet or anticoagulant medications [192].

The use of mechanical prophylaxis in certain high risk cases after standard polypectomy or EMR should be individualized on the basis of patient or polyp risk factors. A clinical risk score derived from a prospective multicenter dataset of more than 2000 colonic EMRs has recently been described. Importantly, it is simple to use and independently confirms the key risk factors identified in previous studies [193], including lesion size $>30 \mathrm{~mm}$, proximal colon location, and presence of major co-morbidity. Further research regarding prophylactic therapies in this high risk group is required. 


\section{RECOMMENDATION}

Patients admitted to hospital with delayed bleeding who are hemodynamically stable, without ongoing bleeding, may be initially managed conservatively. If intervention is required, ESGE recommends colonoscopy as the firstline investigation. (Moderate quality evidence, strong recommendation.)

PPB is one of the most common causes of lower gastrointestinal bleeding amenable to endotherapy [194]. Not all patients presenting with PPB need urgent colonoscopy; however a clear means of identifying those that do has not been defined. No relevant study has been conducted and only expert opinion exists. Patients responding to resuscitation should initially be observed [195]. If bleeding persists, patients should be given an adequate bowel preparation and repeat colonoscopy performed [196,197]. Using a decision model it was calculated that a tandem colonoscopy for identification and treatment of PPB is beneficial in about $22 \%$ of patients [198]. In a multicenter, prospective study of colonic lesions $\geq 20 \mathrm{~mm}$ treated by EMR, $55 \%$ of patients avoided repeat colonoscopy because bleeding spontaneously stopped. When colonoscopy was performed, endoscopic therapy was only necessary in 21 of 27 cases (70\%). On the basis of these data, a risk-based algorithm for the management of PPB has been proposed [199].

\section{RECOMMENDATION}

When the polypectomy site is identified during colonoscopy for post-polypectomy bleeding, and active bleeding or other high risk stigmata are identified, ESGE recommends forceps coagulation or mechanical therapy, with or without the combined use of dilute adrenaline injection. (Moderate quality evidence; strong recommendation.)

The optimal technique for achieving endoscopic hemostasis in cases of active PPB or other high risk stigmata has not been determined. Technique selection is based on location and characteristics of the lesion, endoscopist preference and experience, and device availability. The most commonly used methods are clipping, or forceps coagulation with or without the combined use of adrenaline injection [124, 195, 200, 201]. Clipping, with or without adrenaline injection, may be superior to forceps coagulation therapy since it limits further tissue injury. Caution is necessary during the application of hemostatic techniques, as transmural injury from thermocoagulation and perforation during clipping have been reported among other complications [124]. Endoscopic band ligation has also been used to manage PPB in cases of pedunculated or semipedunculated polyps [202, 203].

\subsection{Prevention of perforation}

\section{RECOMMENDATION}

ESGE recommends careful inspection of the post-resection mucosal defect to identify features of or risk factors for impending perforation. Where these risk factors are identified, clip closure should be performed. (Moderate quality evidence; strong recommendation.)

Careful analysis of the post-resection mucosal defect is a critical part of polypectomy, particularly in wide-field EMR. Injury to the muscularis propria layer should be identified before it becomes a frank perforation where surgical treatment is mandatory. Full-thickness perforation needs immediate closure endoscopically or surgically [204]. Thorough inspection of the postEMR specimen and resection defect may reveal the "target sign," a marker of either partial- or full-thickness muscularis propria resection and imminent perforation. In these cases, immediate endoscopic clipping is indicated $[5,205]$. Incorporation of a blue chromic dye into the submucosal injectate facilitates inspection of the submucosal defect which should appear as a relatively homogeneous blue mat of intersecting obliquely oriented submucosal fibres. Topical submucosal chromoendoscopy is a simple and effective technique that rapidly confirms the level of resection and may improve detection of intraprocedural perforation [157]. Endoscopic signs such as exposure of the muscularis propria layer, submucosal fibrosis, or submucosal fat should be noted and further evaluated by topical submucosal chromoendoscopy. Areas that stain poorly because of submucosal fibrosis should be treated by clip closure, since they do not allow endoscopic exclusion of muscularis propria injury and carry a risk of delayed perforation [82, 206].

Risk factors for deep mural injury include attempted en bloc snare excision for lesions $\geq 25 \mathrm{~mm}$, high grade dysplasia/early cancer, and transverse colon location.

\subsection{Audit of adverse events}

\section{RECOMMENDATION}

ESGE recommends audit of adverse events. (Moderate quality evidence; strong recommendation.)

Methods of collecting data on adverse events following endoscopic procedures, including colorectal polypectomy, are not uniform and vary from nonsystematic self-reporting to complete registry reporting including linkage to databases other than endoscopic ones. One study revealed that the different methods of collecting data may result in up to 3.1-fold differences in reported frequency of adverse events [206]. A uniform methodology for auditing immediate and delayed (up to 30 days) adverse events is required and studies on completeness of data are needed. One such methodology of auditing polypectomy complications was described in a study from Munich 
[128]. Other proposals include the creation of obligatory national databases of adverse events, as proposed in the Netherlands, together with systematic quality assurance programs. Additionally, ESGE guidelines concerning definitions and reporting of adverse events should be followed and usage should be audited [205].

However, currently no systematic audits concerning polypectomy complications are functioning outside of research studies. Optimally an audit should contain: (a) immediate selfreporting by the endoscopic service; (b) 30-day structured telephone interview or patient questionnaire followed by telephone contact, in the case of no face-to-face contact; and (c) linkage to a national hospitalizations database.

\section{How is the histology specimen best managed and reported upon? Processing, analysis, and report- ing (minimum reporting standards)}

\section{RECOMMENDATION}

ESGE recommends that polypectomy specimens be placed in separate containers, one for each lesion. Local factors may play a role in whether this is feasible. Fixation should be by buffered $10 \%$ formalin. The pathologist should measure the size of each specimen in millimeters. (Moderate quality evidence; strong recommendation.)

\section{RECOMMENDATION}

ESGE suggests that large $(\geq 20 \mathrm{~mm})$ sessile lesions removed en bloc, or lesions suspicious for submucosal invasion removed piecemeal, should be pinned to cork to optimize histological assessment. (Low quality evidence; weak recommendation.)

\section{RECOMMENDATION}

ESGE recommends that specimens be sliced and totally embedded, allowing the identification of the deep and lateral margins. (Moderate quality evidence; strong recommendation.)

The pathological work-up of the resection specimens plays a central role in the management of patients undergoing colorectal polypectomy. The quality and accuracy of the histopathological diagnosis directly affect clinical management and decision-making, ranging from surveillance to further local and/or major resection. Multidisciplinary evidence-based guidelines for quality assurance in colorectal cancer screening have recently been developed by a group of experts in a project coordinated by the International Agency for Research on Cancer (IARC) and co-funded by the Public Health Programme of the European Union [207]. The guidelines' pathology content has been published in four papers in both pathological [208, 209] and clinical $[210,211]$ journals. These publications define the current standard of care in the pathological work-up of polypectomy specimens, in Europe and beyond. The following subsection is a brief summary.

\subsection{Technical considerations}

Specimen handling is an important issue, as poor handling and dissection procedures can impair diagnostic accuracy. Specimen handling starts with the endoscopic removal and ends with the histopathological diagnosis and report [208,210]. It is recommended that specimens be placed in separate containers, one for each lesion. This helps to avoid confusion about the exact location of the lesion(s), and also increases the accuracy of histopathological diagnosis by avoiding false-positive diagnoses of mixed lesions, e.g. sessile serrated adenomas with dysplasia. Biopsies from the same lesion can be placed in the same container. Fixation should be by buffered $10 \%$ formalin. Specimens can shrink due to formalin fixation, therefore measurements taken after fixation can differ from those prior to fixation [208, 210].

Size is an important objective measurement, best performed by the pathologist. Pathology measurements are auditable, accurate, and simple to perform [210]. Lesion size should be given in millimeters. If possible, the maximum size should be measured from the histological slide, and only measured from the formalin-fixed gross specimen if the lesion is disrupted or too large [211].

Polypoid lesions must be sliced and totally embedded. While smaller lesions may be bisected through the stalk, larger lesions should be trimmed to generate a central section containing the intact stalk for further analysis. As the pathology report should verify the complete removal of a neoplastic lesion, special attention needs to be paid to the evaluation of the resection margin, which should be identified and described (broad, stalked, etc.) and either dissected tangentially into an extra cassette or sliced in a way that allows complete assessment [208,210].

It is recommended that the resections of sessile or flat lesions be pinned out (mucosal surface upwards), e. g. on a piece of cork or other suitable material, by inserting pins through the periphery of the specimens. Needles should not be placed directly through a lesion. After fixation, the specimens are described and sectioned transversely into 3-mm slices (submitted for histological evaluation in sequentially labelled cassettes), thereby allowing the identification of involvement of the deep and lateral margins. Particular attention should be paid to any areas of ulceration or induration for signs of invasion [208, 210].

Piecemeal resection precludes a reliable assessment of completeness of resection. Whenever possible, the entire lesion should be embedded to allow exclusion of invasive malignancy.

Inking of margins is recommended. The distance to the excisional margin should be reported in millimeters. The European guidelines recommend that clearance of $1 \mathrm{~mm}$ or less indicates margin involvement $[208,210]$. Cases of incomplete removal should be highlighted, which is most important for advanced adenomas and early cancer. Three or more levels should be cut through each block and stained with hematoxylin and eosin $[208,210]$. 


\subsection{Adenoma grading, and reporting of cytological dysplasia}

\section{RECOMMENDATION}

ESGE recommends the grading of adenomas/neoplasia as low grade or high grade according to the World Health Organization (WHO) classification. (High quality evidence; strong recommendation.)

\section{RECOMMENDATION}

ESGE recommends that sessile serrated adenomas/polyps should be reported as containing cytological dysplasia when it is present. (Moderate quality evidence; strong recommendation.)

\section{Diagnosis of lesions in the adenoma-carcinoma sequence}

\subsection{Lesion types}

Colorectal adenoma is defined as a lesion in the colon or rectum containing unequivocal (intra)epithelial neoplasia (dysplasia) [212]. Classification of adenomas should include grading of neoplasia according to the revised Vienna classification to apply a two-tiered categorization of low grade and high grade neoplasia. This system aims to minimize intraobserver and interobserver variation and to facilitate the management of endoscopically detected lesions by improving correlation between the histopathology of biopsy and resection specimens.

Most adenomas measure less than $10 \mathrm{~mm}$ in size and have tubular architecture. Villous architecture is defined as leaflike or fingerlike projections of epithelium overlying a small amount of lamina propria. Tubulovillous adenomas are defined by a mixture of tubular and villous structures, with arbitrary percentages in different studies, typically with between $25 \%$ and $75 \%$ villous component. Grading of neoplasia is performed by assessing the degree of architectural complexity, the extent of nuclear stratification, and the severity of abnormal nuclear morphology [213].

Approximately one third of colorectal cancers develop from serrated lesions, a heterogeneous group of lesions characterized morphologically by a serrated (sawtoothed or stellate) architecture of the epithelial compartment. Hyperplastic polyps, sessile serrated adenomas/polyps, and traditional serrated adenomas are the lesions included in this group [213].

Hyperplastic polyps are very common, accounting for $70 \%$ to $95 \%$ of all serrated lesions, or $25 \%-30 \%$ of resected polyps $[214,215]$. They occur as usually small $(<5 \mathrm{~mm})$ nondysplastic polyps in the left colon, particularly the sigmoid colon and rectum, and only rarely in the right colon [213-215].

Sessile serrated adenomas/polyps are more likely to be located in the right colon (75\%), accounting for approximately $5 \%-25 \%$ of all serrated lesions $[213,216]$. Their size is larger than that of hyperplastic polyps: More than half of the lesions measure $>5 \mathrm{~mm}$ and $15 \%-20 \%$ of the lesions $>10 \mathrm{~mm}$, respectively.
They may develop de novo or from pre-existing hyperplastic polyps. Upon histological examination, sessile serrated adenomas/polyps show distorted crypt architecture, with hyperserration, often at the base of the crypts, and with dilated, mucus-filled, L-shaped ("boot") and T-shaped ("anchor") crypts [214-219]. Uncomplicated sessile serrated adenomas/polyps are nondysplastic, but they may acquire overt dysplasia during tumor progression, often in conjunction with methylation of the hMLH1 gene promoter [213-215, 217].

Traditional serrated adenomas are rare, accounting for only about $1 \%$ of colorectal polyps. They prevail in the left colon. They are often polypoid or pedunculated, but sessile lesions do also occur, predominantly in the right colon $[220,221]$.

Early colorectal cancer is defined as invasive adenocarcinoma invading into but not beyond the submucosa [212]. The term 'malignant polyp' refers to an adenoma that appears benign endoscopically, but which shows invasion through the muscularis mucosa into the submucosa upon histological assessment. A malignant polyp is therefore an early carcinoma. Malignant polyps account for $0.75 \%$ to $5.6 \%$ of large-bowel polyps removed in general diagnostic colonoscopy practice [102].

Patient management following endoscopic removal of a malignant polyp is difficult because of the potential risk of residual cancer tissue within the bowel wall and/or metastatic cancer spread to regional lymph nodes. The depth of invasion into the submucosal layer, assessed according to the Haggitt classification $[17,102]$ (for pedunculated lesions), the Kikuchi classification [222] (for nonpolypoid lesions), or by direct measurement (in microns from the bottom line of the muscularis mucosae), has been associated with regional lymph node spread. Angioinvasion, in particular lymphatic invasion, poor tumor differentiation or grade, and resection margin status have been identified as additional risk factors $[223,224]$. The combined assessment of these features increases the accuracy of risk prediction [102, $225,226]$ and allows the stratification of patients into low risk and high risk groups [102, 227, 228].

\subsection{Histological findings that require further action}

\section{RECOMMENDATION}

ESGE recommends that where submucosal invasion is present, the depth of invasion should be measured and reported, in addition to other risk factors, such as poor differentiation, lymphovascular invasion and tumor budding. The distance to the deep/vertical and to the lateral/horizontal resection margin should be measured and reported. (Moderate quality evidence; strong recommendation.)

\section{RECOMMENDATION}

The opinion of a second histopathologist may be warranted when reviewing high risk features. (Low quality evidence; weak recommendation) 
Endoscopic resection is an effective cure for colorectal lesions confined to the mucosa. Invasion across the muscularis mucosa into the submucosa constitutes T1 disease. Complete resection of a T1 lesion is often readily achievable; however even if completely resected, T1 tumors are associated with a risk of lymph node metastasis (LNM) which, if present, has a significant impact on survival and cure. The 5-year survival for a T1 lesion without LNM (stage 1) is $>95 \%$, whereas T1 disease with any LNM (stage III) reduces overall 5 year survival to $68.4 \%-87.6 \%$ [229]. Surgery and lymph node dissection is essential in those with suspected LNM to completely stage the disease and improve outcomes.

LNM is present with a minority of T1 cancers (6.3\%-17.6\%) (see Table 14, Appendix 2; available online in Supplementary material); thus the majority of patients may be cured by endoscopic resection alone. Although definitive, surgery for colorectal cancer is costly, invasive, and can be associated with significant morbidity and mortality [66, 230]. Risk stratification of T1 lesions is therefore important to identify patients at low risk of LNM who may safely avoid surgery.

There are a large number of studies that aim to address risk factors for LNM; however the majority are small and retrospective. Many studies are restricted to surgically resected tumors, potentially producing a bias towards larger and higher grade lesions. The most commonly identified risk factors for LNM are deep vertical penetration (submucosal invasion $>1000 \mu \mathrm{m}$ for flat or sessile lesions and Haggitt level 4 for pedunculated lesions), lymphovascular invasion, poor tumor differentiation, tumor budding, and a positive resection margin. There are no identified clinical or patient features which are reliably associated with LNM, aside from rectal location [224].

\subsection{Submucosal invasion depth}

Methods for classifying the extent of submucosal invasion vary depending on the morphology of the polyp, and are prone to interobserver variation. The most established classification methods are Haggitt levels [102] for pedunculated lesions and Kikuchi levels [222] for flat or sessile lesions.

The Haggitt classification divides the polyp into five zones. Level 0 is noninvasive disease which does not cross the muscularis mucosa. Levels 1-4 describe progressive involvement of head, stalk, and submucosa below the stalk. In a small series $(n=129)$, Haggitt et al. showed that the deepest level of invasion (level 4) was associated with LNM or death from colorectal cancer [102]. The system is widely adopted, and endoscopically resected level 1-3 disease has been shown to be associated with a low risk of LNM $[103,231]$. Despite this, studies have described LNM with $6.2 \%-8.0 \%$ of polyps with level 3 invasion [232]. Pathological assessment of Haggitt levels may be hampered by endoscopic trauma and cautery artefact during removal, by shrinkage after fixation, and by suboptimal tissue orientation due to the plane of sectioning.

For nonpolypoid lesions, depth of submucosal invasion can be classified using the Kikuchi level system. Kikuchi et al. adapted an existing schema whereby sm1, sm2, and sm3 denote the upper, middle, and lower thirds of the submucosa respectively [14]. Reported risks of LNM are $0-3 \%$ for sm 1 in- vasion, $8 \%-10 \%$ for sm 2 , and $23 \%-25 \%$ for sm3 [222, 233]. The classification cannot be applied when lesions have been resected endoscopically, as the muscularis propria is not included. As a result, some authors have proposed using a measurement of the distance of invasion from the muscularis mucosa. Ueno et al. described an elevated risk of LNM when invasion extends deeper than $2000 \mu \mathrm{m}$ beyond the muscularis mucosa $(2.5 \%$ vs. $18.2 \%)$ or when the invasion width is $>4000 \mu \mathrm{m}$ (3.9\% vs. $17.1 \%$ ) [225]. In a retrospective UK study, invasion width (>11.5 mm) and area were also found to be risk factors for LNM after multivariable adjustment for other significant risk factors (grade of differentiation, lymphatic and vascular invasion) [234]. Four meta-analyses have shown that invasion $>1000 \mu \mathrm{m}$ is a risk factor for LNM, although all four studies comment on the small sizes, heterogeneity, and retrospective nature of the included papers [104, 224, 235, 236].

\subsection{Lymphovascular invasion}

The majority of studies examining histological risk factors for LNM report on lymphatic or vascular invasion. Five meta-analyses have all demonstrated that lymphatic or lymphovascular invasion is one of the stronger risks for LNM [104, 224, 235 - 237]. In patients undergoing surgery for T1 lesions, lymphatic invasion is reported in $27 \%-31 \%$ and approximately $27 \%$ of these patients have LNM. Vascular invasion, when separately reported, is seen in $19 \%$ with LNM in $21 \%-24 \%$ [224, 235].

It may be difficult to detect lymphatic invasion by standard light microscopy because of retraction artifact, which can result in an artificial space surrounding tumor nests that mimics a lymphatic channel. The use of immunohistochemistry with an antihuman podoplanin antibody such as D2-40 may improve the ability to detect and characterize lymphoid invasion [238]. A meta-analysis of histopathological predictive factors showed that the strongest predictive factors for LNM were lymphatic vessel invasion identified by an antihuman podoplanin antibody (OR 5.19, $95 \% \mathrm{Cl} 3.31-8.15 ; P=0.01)$ or tumor budding (OR 7.45, $95 \% \mathrm{Cl} 4.27$ - 13.02; $P=0.0077$ ) [237]. Immunohistochemical markers such as D2-40 are not in widespread use.

\subsection{Tumor differentiation}

Grading of colorectal carcinomas should be performed according to the WHO classification, and tumors are graded as well-differentiated (>95\% gland formation), moderately differentiated ( $50 \%-95 \%$ gland formation), or poorly differentiated ( $<50 \%$ gland formation). Carcinomas may be heterogeneous, so the tumor should be graded according to the least differentiated component. The interobserver agreement between pathologists when grading colorectal adenocarcinoma specimen is fair at best, and it has been suggested that use of the high grade and low grade categories should be standardized [239].

High grade, or poorly differentiated tumors are associated with LNM and residual disease following endoscopic resection. In a pooled analysis of retrospective studies, Hassan et al. reported poor differentiation in $116 / 1612$ polyps (7.2\%) [227]. In patients with poor differentiation LNM was apparent in $23 \%$ 
compared to $7 \%$ with low grade changes. Poor differentiation was also associated with hematogenous metastases and mortality. A meta-analysis of sessile early colorectal cancer showed an RR of 8.19 (95\% Cl $4.65-14.43)$ for LNM in poorly compared to well-differentiated tumors and of $3.48(95 \% \mathrm{Cl} 2.08-5.81)$ for poor compared to moderate differentiation [236]. Two other meta-analyses of more heterogeneous studies also confirmed this association of LNM with poor differentiation with RRs of $5.60(95 \% \mathrm{Cl} 2.90-10.82 ; P<0.001)$ [104] and $4.8(95 \%$ Cl $3.3-6.9 ; P<0.001)$ [224].

\subsection{Tumor budding}

Budding refers to the presence of single cells or small groups of tumor cells scattered within the stroma at the leading edge of invasion. Several studies have identified this feature as a risk factor for LNM [240, 241], and it is associated with venous and lymphatic invasion [242] as well as with poorer outcome in colorectal cancer [243]. In early colorectal cancer, tumor budding has been reported primarily in Japanese studies. Its assessment suffers from a lack of standardized international criteria. Usually, budding is either described as present or absent, or it is graded. Despite this lack of conformity (high grade) budding has been associated reliably with LNM and has hence been identified as a strong and independent predictor of LNM in five meta-analyses [104, 224, 235-237]. Prospective studies, and a consensus definition for the reporting of tumor budding are required for the inclusion of this characteristic in standard histopathological reporting of T1 cancer.

\subsection{Resection margin}

Involvement of the deep resection margin is associated with residual tumor, hematogenous metastasis, and mortality [225, $227,244]$. Margin involvement should be reported routinely by the pathologist and clearance from the resection margin should be described and measured in millimeters.

There is no generally accepted consensus definition, and a positive margin has been defined variably as cancer within the diathermy margin, within one high power field of the margin [225, 245, 246], $0.1 \mathrm{~mm}$ or less from the margin [247], $1 \mathrm{~mm}$ or less from the margin $[248,249]$, or $2 \mathrm{~mm}$ or less from the margin $[250,251]$. Residual tumor or recurrence is $<2 \%$ where the margin of resection is $>1 \mathrm{~mm}$ and in the absence of other unfavorable histological features [223,247,252,253]. Cunningham et al. reported that in the absence of unfavorable factors, $16.6 \%$ of polyps with a margin clearance $\leq 1 \mathrm{~mm}$ had residual disease at surgery [254]. Cooper et al. showed in a retrospective single-center study that in patients without risk factors but where margin clearance was $\leq 1 \mathrm{~mm}$, an adverse outcome (endoscopic recurrence, tumor in the surgical specimen, or LNM) was present in $19.4 \%$. By contrast, there were no adverse outcomes in low risk patients with margins $>1 \mathrm{~mm}$ [249]. Resection margins of $>2 \mathrm{~mm}$ are associated with very low rates of recurrence [251]. However the inclusion of a $<2$ $\mathrm{mm}$ margin as an unfavorable risk factor may result in overtreatment of lesions without other risk factors [255]. Unequivocal deep margin involvement is certainly an unfavorable risk factor and further resection is required, with the modality (sur- gical resection or transanal endoscopic microsurgery [TEMS]) based on tumor location and patient co-morbidities. Clearance of $\leq 1 \mathrm{~mm}$ is associated with similar outcomes to definite margin involvement, and clearance $>1 \mathrm{~mm}$ appears to be helpful in defining low risk patients. Other European guidelines currently recommend a level of $\leq 1 \mathrm{~mm}$ as equivalent to margin involvement [256, 257].

\subsection{Combined risk assessment}

Several risk factors have been established as high risk features for the prediction of LNM or residual disease in endoscopically resected lesions containing a malignant focus. These factors include deep submucosal invasion (>1000 $\mu \mathrm{m}$ for flat or sessile lesions and Haggitt level 4 for pedunculated lesions), lymphovascular invasion, poor tumor differentiation, tumor budding, and a positive resection margin. Consequently, all these factors should be addressed in the pathology report in order to provide clinicians with a risk estimate for discussing further management in a multidisciplinary setting and with the patient [256]. The combination of risk factors is important, as an absence of defined high risk features has been shown to identify a "low risk group" of patients. Patients in this low risk group may still have a small risk of LNM and they should be followed as such.

\section{Conclusion}

This ESGE Guideline comprehensively addresses critical areas in the assessment and management of colorectal polyps. Polypectomy is among the most important colonoscopy skills. The ability to perform complete and safe polypectomy enables us to significantly benefit our patients. Mastery of basic polypectomy, and an understanding of the issues involved in advanced polypectomy, should be goals of all colonoscopists.

The diverse topics covered in this polypectomy and EMR Guideline include the classification of colorectal polyps, the optimal evidence-based approaches to polypectomy for polyps of all sizes and morphologies, colonic tattooing, a guide to effective and safe EMR for large sessile polyps, the role of advanced imaging in polypectomy, and which lesions require the involvement of expert centers or more complex interventions such as ESD or surgery. Technical aspects such as equipment and auxiliary devices to optimize polypectomy are also discussed. The Guideline defines the key adverse events during and following polypectomy, the recommended management of adverse events, and the need for audit of outcomes to monitor quality and safety of polypectomy and EMR. Finally, guidelines for the histological evaluation of resected polypectomy specimens and practice recommendations for high risk histological features are discussed. Throughout this Guideline, areas where further research is required to answer critical questions are highlighted, providing direction for researchers to design further studies. We look forward to the opportunity to incorporate the results of such studies into updates of this Guideline in the years to come. 
ESGE guidelines represent a consensus of best practice based on the available evidence at the time of preparation. They may not apply in all situations and should be interpreted in the light of specific clinical situations and resource availability. Further controlled clinical studies may be needed to clarify aspects of the statements, and revision may be necessary as new data appear. Clinical consideration may justify a course of action at variance to these recommendations. ESGE guidelines are intended to be an educational device to provide information that may assist endoscopists in providing care to patients. They are not a set of rules and should not be construed as establishing a legal standard of care or as encouraging, advocating, requiring, or discouraging any particular treatment.

\section{Competing interests}

P. Bhandari has served on Advisory Boards for Fujifilm, Pentax, and Boston Scientific (1 Nov 2015-31 Dec 2016, for all); he has participated in preparation of similar guidelines for the British Society of Gastroenterology (BSG). P. Fockens provides ongoing consultancy to Cook, Olympus, Medtronic, and Fujifilm. L. Moons' department has received a grant from Boston Scientific (1 Jan 2016- 1 January 2017.J. Pohl provides consultancy to Karl Storz (Jan 2016 - ). T. Ponchon has provided consultancy to Olympus, Boston Scientific, and Cook Medical (2007 - 2016, for all); his department has received financial support for clinical research from Boston Scientific. M. Rutter's department received an unrestricted grant for a trial (non-polypectomy) from Olympus (2013-2016); he is a member of the BSG (2000-). The following authors have no competing interests: M. Bronzwaer, M. Bourke, N. Burgess, J.-M. Dumonceau, M. Ferlitsch, I. Gralnek, M. Gschwantler, C. Hassan, R. Hazzan, D. Heresbach, P. Jeschek, R. Jover, C. Langner, A. Lemmers, A. Moss, K. Nalankilli, K. Paraskeva, G. Paspatis, D. Penz, J. Regula, A. Repici, E. Waldmann.

\section{References}

[1] Zauber AG, Winawer S], O'Brien M] et al. Colonoscopic polypectomy and long-term prevention of colorectal-cancer deaths. N Engl J Med 2012; 366: 687-696

[2] Bretthauer M, Kaminski MF, Loberg M et al. Population-based colonoscopy screening for colorectal cancer: a randomized clinical trial. JAMA Intern Med 2016; 176: 894-902

[3] Brenner H, Stock C, Hoffmeister M. Effect of screening sigmoidoscopy and screening colonoscopy on colorectal cancer incidence and mortality: systematic review and meta-analysis of randomised controlled trials and observational studies. BMJ 2014; 348: g2467

[4] Moss A, Bourke M], Williams SJ et al. Endoscopic mucosal resection outcomes and prediction of submucosal cancer from advanced coIonic mucosal neoplasia. Gastroenterology 2011; 140: 1909-1918

[5] Swan MP, Bourke M], Moss A et al. The target sign: an endoscopic marker for the resection of the muscularis propria and potential perforation during colonic endoscopic mucosal resection. Gastrointest Endosc 2011; 73: 79-85
[6] Britto-Arias M, Waldmann E, Jeschek P et al. Forceps versus snare polypectomies in colorectal cancer screening: are we adhering to the guidelines? Endoscopy 2015; 47: 898- 902

[7] Veitch AM, Vanbiervliet G, Gershlick AH et al. Endoscopy in patients on antiplatelet or anticoagulant therapy, including direct oral anticoagulants: British Society of Gastroenterology (BSG) and European Society of Gastrointestinal Endoscopy (ESGE) guidelines. Endoscopy 2016; 48: $385-402$

[8] Hassan C, Quintero E, Dumonceau JM et al. Post-polypectomy colonoscopy surveillance: European Society of Gastrointestinal Endoscopy (ESGE) Guideline. Endoscopy 2013; 45: 842 - 851

[9] Rembacken B, Hassan C, Riemann JF et al. Quality in screening colonoscopy: position statement of the European Society of Gastrointestinal Endoscopy (ESGE). Endoscopy 2012; 44: 957 - 968

[10] Atkins D, Best D, Briss PA et al. Grading quality of evidence and strength of recommendations. BMJ 2004; 328: 1490

[11] Dumonceau JM, Hassan C, Riphaus A et al. European Society of Gastrointestinal Endoscopy (ESGE) Guideline Development Policy. Endoscopy 2012; 44: 626-629

[12] [Anonymous] The Paris endoscopic classification of superficial neoplastic lesions: esophagus, stomach, and colon: November 30 to December 1, 2002. Gastrointest Endosc 2003; 58: S3-43

[13] Endoscopic Classification Review Group. Update on the Paris classification of superficial neoplastic lesions in the digestive tract. Endoscopy 2005; 37: 570-578

[14] Kudo S. Endoscopic mucosal resection of flat and depressed types of early colorectal cancer. Endoscopy 1993; 25: 455-461

[15] Bianco MA, Cipolletta L, Rotondano G et al. Prevalence of nonpolypoid colorectal neoplasia: an Italian multicenter observational study. Endoscopy 2010; 42: 279-285

[16] Saitoh Y, Obara T, Watari J et al. Invasion depth diagnosis of depressed type early colorectal cancers by combined use of videoendoscopy and chromoendoscopy. Gastrointest Endosc 1998; 48: 362 370

[17] Uraoka T, Saito Y, Matsuda T et al. Endoscopic indications for endoscopic mucosal resection of laterally spreading tumours in the colorectum. Gut 2006; 55: 1592-1597

[18] Pohl H, Srivastava A, Bensen SP et al. Incomplete polyp resection during colonoscopy-results of the complete adenoma resection (CARE) study. Gastroenterology 2013; 144: 74-80.e71

[19] van Doorn SC, Hazewinkel Y, East JE et al. Polyp morphology: an interobserver evaluation for the Paris classification among international experts. Am J Gastroenterol 2015; 110: 180 - 187

[20] Kudo Se, Lambert R, Allen Jl et al. Nonpolypoid neoplastic lesions of the colorectal mucosa. Gastrointest Endosc 2008; 68: S3-47

[21] Lambert R, Kudo S, Vieth M et al. Pragmatic classification of superficial neoplastic colorectal lesions. Gastrointest Endosc 2009; 70: $1182-1199$

[22] Kamiński MF, Hassan C, Bisschops R et al. Advanced imaging for detection and differentiation of colorectal neoplasia: European Society of Gastrointestinal Endoscopy (ESGE) Guideline. Endoscopy 2014; 46: DOI: $10.1055 / \mathrm{s}-0034-1365348$

[23] Rex DK, Kahi C, O’Brien M et al. The American Society for Gastrointestinal Endoscopy PIVI (Preservation and Incorporation of Valuable Endoscopic Innovations) on real-time endoscopic assessment of the histology of diminutive colorectal polyps. Gastrointest Endosc 2011; 73: $419-422$

[24] Abu Dayyeh BK, Thosani N, Konda V. ASGE Technology Committee. et al. ASGE Technology Committee systematic review and meta-analysis assessing the ASGE PIVI thresholds for adopting real-time endoscopic assessment of the histology of diminutive colorectal polyps. Gastrointest Endosc 2015; 81: 502.e501-502.e516 
[25] Basford P, Longcroft-Wheaton G, Bhandari P. ASGE Technology Committee reviews on real-time endoscopic assessment of the histology of diminutive colorectal polyps, and high-definition and highmagnification endoscopes. Gastrointest Endosc 2015; 82: 1139 1140

[26] Dayyeh BA, Banerjee S. Response. Gastrointest Endosc 2015; 82 : $1140-1141$

[27] Lee CK, Shim JJ, Jang JY. Cold snare polypectomy vs. cold forceps polypectomy using double-biopsy technique for removal of diminutive colorectal polyps: a prospective randomized study. Am J Gastroenterol 2013; 108: $1593-1600$

[28] Kim JS, Lee BI, Choi H et al. Cold snare polypectomy versus cold forceps polypectomy for diminutive and small colorectal polyps: a randomized controlled trial. Gastrointest Endosc 2015; 81: 741 - 747

[29] Efthymiou M, Taylor AC, Desmond PV et al. Biopsy forceps is inadequate for the resection of diminutive polyps. Endoscopy 2011; 43: $312-316$

[30] Jung YS, Park JH, Kim HJ et al. Complete biopsy resection of diminutive polyps. Endoscopy 2013; 45: 1024-1029

[31] Aslan F, Cekic C, Camci M et al. What is the most accurate method for the treatment of diminutive colonic polyps? Standard versus jumbo forceps polypectomy Medicine (Baltimore) 2015; 94: e621

[32] Peluso F, Goldner F. Follow-up of hot biopsy forceps treatment of diminutive colonic polyps. Gastrointest Endosc 1991; 37: 604-606

[33] Paspatis GA, Vardas E, Charoniti I et al. Bipolar electrocoagulation vs conventional monopolar hot biopsy forceps in the endoscopic treatment of diminutive rectal adenomas. Colorectal Dis 2005; 7: $138-142$

[34] Yasar B, Kayadibi H, Abut E et al. The histological quality and adequacy of diminutive colorectal polyps resected using jumbo versus hot biopsy forceps. Dig Dis Sci 2015; 60: 217-225

[35] Weston AP, Campbell DR. Diminutive colonic polyps: histopathology, spatial distribution, concomitant significant lesions, and treatment complications. Am J Gastroenterol 1995; 90: 24-28

[36] Savides TJ, See JA, Jensen DM et al. Randomized controlled study of injury in the canine right colon from simultaneous biopsy and coagulation with different hot biopsy forceps. Gastrointest Endosc 1995; 42: $573-578$

[37] Metz AJ, Moss A, McLeod D et al. A blinded comparison of the safety and efficacy of hot biopsy forceps electrocauterization and conventional snare polypectomy for diminutive colonic polypectomy in a porcine model. Gastrointest Endosc 2013; 77: 484-490

[38] Pohl H, Srivastava A, Bensen SP et al. Incomplete polyp resection during colonoscopy-results of the complete adenoma resection (CARE) study. Gastroenterology 2013; 144: 74-80 e71

[39] Horiuchi A, Nakayama Y, Kajiyama M et al. Removal of small colorectal polyps in anticoagulated patients: a prospective randomized comparison of cold snare and conventional polypectomy. Gastrointest Endosc 2014; 79: 417-423

[40] Paspatis GA, Tribonias G, Konstantinidis K et al. A prospective randomized comparison of cold vs hot snare polypectomy in the occurrence of postpolypectomy bleeding in small colonic polyps. Colorectal Dis 2011; 13: e345-348

[41] Ichise Y, Horiuchi A, Nakayama Y et al. Prospective randomized comparison of cold snare polypectomy and conventional polypectomy for small colorectal polyps. Digestion 2011; 84: 78-81

[42] Voiosu TA, Margarit C, Rimbas M et al. Polypectomy practices in a real life setting. Do we do enough for our patients? A review of 1061 colonoscopies Rom J Intern Med 2011; 49: 257-265

[43] Muniraj T, Sahakian A, Ciarleglio MM et al. Cold snare polypectomy for large sessile colonic polyps: a single-center experience. Gastroenterol Res Pract 2015; 2015: 175959
[44] Augusto Barros R, Monteverde M], Federico Barros R et al. [Safety and efficacy of cold snare resection of non-polypoid colorectal lesions (0-Ila and 0-IIb)]. Acta Gastroenterol Latinoam 2014; 44: 27 32

[45] Dobrowolski S, Dobosz M, Babicki A et al. Blood supply of colorectal polyps correlates with risk of bleeding after colonoscopic polypectomy. Gastrointest Endosc 2006; 63: 1004-1009

[46] Watabe H, Yamaji Y, Okamoto M et al. Risk assessment for delayed hemorrhagic complication of colonic polypectomy: polyp-related factors and patient-related factors. Gastrointest Endosc 2006; 64: $73-78$

[47] Kim HS, Kim TI, Kim WH et al. Risk factors for immediate postpolypectomy bleeding of the colon: a multicenter study. Am J Gastroenterol 2006; 101: $1333-1341$

[48] Buddingh KT, Herngreen T, Haringsma J et al. Location in the right hemi-colon is an independent risk factor for delayed post-polypectomy hemorrhage: a multi-center case-control study. Am J Gastroenterol 2011; 106: 1119-1124

[49] Di Giorgio P, De Luca L, Calcagno G et al. Detachable snare versus epinephrine injection in the prevention of postpolypectomy bleeding: a randomized and controlled study. Endoscopy 2004; 36: 860 863

[50] lishi H, Tatsuta M, Narahara $\mathrm{H}$ et al. Endoscopic resection of large pedunculated colorectal polyps using a detachable snare. Gastrointest Endosc 1996; 44: 594-597

[51] Dobrowolski S, Dobosz M, Babicki A et al. Prophylactic submucosal saline-adrenaline injection in colonoscopic polypectomy: prospective randomized study. Surg Endosc 2004; 18: 990 - 993

[52] Lee SH, Chung IK, Kim S] et al. Comparison of postpolypectomy bleeding between epinephrine and saline submucosal injection for large colon polyps by conventional polypectomy: a prospective randomized, multicenter study. World J Gastroenterol 2007; 13: 2973 2977

[53] Paspatis GA, Paraskeva K, Theodoropoulou A et al. A prospective, randomized comparison of adrenaline injection in combination with detachable snare versus adrenaline injection alone in the prevention of postpolypectomy bleeding in large colonic polyps. Am J Gastroenterol 2006; 101: 2805; quiz 2913

[54] Kouklakis G, Mpoumponaris A, Gatopoulou A et al. Endoscopic resection of large pedunculated colonic polyps and risk of postpolypectomy bleeding with adrenaline injection versus endoloop and hemoclip: a prospective, randomized study. Surg Endosc 2009; 23: $2732-2737$

[55] Longcroft-Wheaton G, Duku M, Mead R et al. Risk stratification system for evaluation of complex polyps can predict outcomes of endoscopic mucosal resection. Dis Colon Rectum 2013; 56: 960 966

[56] Nanda KS, Tutticci N, Burgess NG et al. Endoscopic mucosal resection of laterally spreading lesions involving the ileocecal valve: technique, risk factors for failure, and outcomes. Endoscopy 2015; 47: $710-718$

[57] Swan MP, Bourke M], Alexander S et al. Large refractory colonic polyps: is it time to change our practice? A prospective study of the clinical and economic impact of a tertiary referral colonic mucosal resection and polypectomy service (with videos) Gastrointest Endosc 2009; 70: $1128-1136$

[58] Kao KT, Giap AQ, Abbas MA. Endoscopic excision of large colorectal polyps as a viable alternative to surgical resection. Arch Surg 2011; 146: $690-696$

[59] Church JM. Experience in the endoscopic management of large coIonic polyps. ANZ J Surg 2003; 73: 988 - 995

[60] Moss A, Williams S], Hourigan LF et al. Long-term adenoma recurrence following wide-field endoscopic mucosal resection (WF-EMR) for advanced colonic mucosal neoplasia is infrequent: results and 
risk factors in 1000 cases from the Australian Colonic EMR (ACE) study. Gut 2015; 64: $57-65$

[61] Buchner AM, Guarner-Argente C, Ginsberg GG. Outcomes of EMR of defiant colorectal lesions directed to an endoscopy referral center. Gastrointest Endosc 2012; 76: 255 - 263

[62] Brooker JC, Saunders BP, Shah SG et al. Endoscopic resection of large sessile colonic polyps by specialist and non-specialist endoscopists. $\mathrm{Br}$ J Surg 2002; 89: 1020 - 1024

[63] Conio M, Repici A, Demarquay JF et al. EMR of large sessile colorectal polyps. Gastrointest Endosc 2004; 60: 234-241

[64] Binmoeller KF, Weilert F, Shah J et al. "Underwater” EMR without submucosal injection for large sessile colorectal polyps (with video). Gastrointest Endosc 2012; 75: 1086 - 1091

[65] Jayanna M, Burgess NG, Singh R et al. Cost analysis of endoscopic mucosal resection vs surgery for large laterally spreading colorectal lesions. Clin Gastroenterol Hepatol 2016; 14: 271 - 278.e271-272

[66] Ahlenstiel G, Hourigan LF, Brown G et al. Actual endoscopic versus predicted surgical mortality for treatment of advanced mucosal neoplasia of the colon. Gastrointest Endosc 2014; 80: 668-676

[67] Keswani RN, Law R, Ciolino JD et al. Adverse events after surgery for benign colon polyps are common and associated with increased length of stay and costs. Gastrointest Endosc 2016; 84: 296-303.e1

[68] Moss A, Nalankilli K. Completing the circle of informed consent for EMR versus surgery for nonmalignant large or complex colorectal polyps. Gastrointest Endosc 2016; 84: 304 - 306

[69] Lee EY, Bourke M]. Endoscopic mucosal resection should be the firstline treatment for large laterally spreading colorectal lesions. Gastrointest Endosc 2016; 64: $326-328$

[70] Pimentel-Nunes P, Dinis-Ribeiro M, Ponchon T et al. Endoscopic submucosal dissection: European Society of Gastrointestinal Endoscopy (ESGE) Guideline. Endoscopy 2015; 47: 829-854

[71] Repici A, Pellicano R, Strangio G et al. Endoscopic mucosal resection for early colorectal neoplasia: pathologic basis, procedures, and outcomes. Dis Colon Rectum 2009; 52: 1502 - 1515

[72] Niimi K, Fujishiro M, Kodashima S et al. Long-term outcomes of endoscopic submucosal dissection for colorectal epithelial neoplasms. Endoscopy 2010; 42: 723 - 729

[73] Repici A, Hassan C, De Paula Pessoa D et al. Efficacy and safety of endoscopic submucosal dissection for colorectal neoplasia: a systematic review. Endoscopy 2012; 44: 137 - 150

[74] Hong YM, Kim HW, Park SB et al. Endoscopic mucosal resection with circumferential incision for the treatment of large sessile polyps and laterally spreading tumors of the colorectum. Clin Endosc 2015; 48: $52-58$

[75] Kim HG, Thosani N, Banerjee S et al. Underwater endoscopic mucosal resection for recurrences after previous piecemeal resection of colorectal polyps (with video). Gastrointest Endosc 2014; 80: 1094 1102

[76] Masci E, Viale E, Notaristefano C et al. Endoscopic mucosal resection in high- and low-volume centers: a prospective multicentric study. Surg Endosc 2013; 27: 3799 - 3805

[77] Kim HH, Kim JH, Park S] et al. Risk factors for incomplete resection and complications in endoscopic mucosal resection for lateral spreading tumors. Dig Endosc 2012; 24: 259-266

[78] Tanaka S, Oka S, Chayama K et al. Knack and practical technique of colonoscopic treatment focused on endoscopic mucosal resection using snare. Dig Endosc 2009; 21: (Suppl. 01): S38-42

[79] Lee EJ, Lee JB, Lee SH et al. Endoscopic treatment of large colorectal tumors: comparison of endoscopic mucosal resection, endoscopic mucosal resection-precutting, and endoscopic submucosal dissection. Surg Endosc 2012; 26: 2220 - 2230

[80] Sakamoto T, Matsuda T, Nakajima T et al. Efficacy of endoscopic mucosal resection with circumferential incision for patients with large colorectal tumors. Clin Gastroenterol Hepatol 2012; 10: 22 26

[81] Bahin FF, Pellise M, Williams S] et al. Extended endoscopic mucosa resection does not reduce recurrence compared with standard endoscopic mucosal resection of large laterally spreading colorectal lesions. Gastrointest Endosc 2016: DOI: 10.1016/j.gie.2016.05.015

[82] Klein A, Bourke MJ. Advanced polypectomy and resection techniques. Gastrointest Endosc Clin N Am 2015; 25: 303 - 333

[83] Belderbos TD, Leenders M, Moons LM et al. Local recurrence after endoscopic mucosal resection of nonpedunculated colorectal lesions: systematic review and meta-analysis. Endoscopy 2014; 46 $388-402$

[84] Desomer L, Tutticci N, Tate DJ et al. A standardized imaging protocol is accurate in detecting recurrence after endoscopic mucosal resection. Gastrointest Endosc 2016: Jun 22. pii: S0016-5107(16)302772. DOI: $10.1016 /$ j.gie.2016.06.031 [Epub ahead of print]

[85] Regula J, Wronska E, Polkowski M et al. Argon plasma coagulation after piecemeal polypectomy of sessile colorectal adenomas: longterm follow-up study. Endoscopy 2003; 35: 212-218

[86] Andrawes S, Haber G. Avulsion: a novel technique to achieve complete resection of difficult colon polyps. Gastrointest Endosc 2014; 80: $167-168$

[87] Veerappan SG, Ormonde D, Yusoff IF et al. Hot avulsion: a modification of an existing technique for management of nonlifting areas of a polyp (with video). Gastrointest Endosc 2014; 80: 884-888

[88] Sakamoto T, Saito Y, Matsuda T et al. Treatment strategy for recurrent or residual colorectal tumors after endoscopic resection. Surg Endosc 2011; 25: $255-260$

[89] Wada Y, Kudo SE, Kashida H et al. Diagnosis of colorectal lesions with the magnifying narrow-band imaging system. Gastrointest Endosc 2009; 70: $522-531$

[90] Oba S, Tanaka S, Oka S et al. Characterization of colorectal tumors using narrow-band imaging magnification: combined diagnosis with both pit pattern and microvessel features. Scand J Gastroenterol 2010; 45: $1084-1092$

[91] Shimura T, Ebi M, Yamada T et al. Magnifying chromoendoscopy and endoscopic ultrasonography measure invasion depth of early stage colorectal cancer with equal accuracy on the basis of a prospective trial. Clin Gastroenterol Hepatol 2014; 12: 662-668 e661-662

[92] Yoshida N, Naito Y, Kugai M et al. Efficacy of magnifying endoscopy with flexible spectral imaging color enhancement in the diagnosis of colorectal tumors. J Gastroenterol 2011; 46: 65-72

[93] Jang HW, Park SJ, Cheon JH et al. Does magnifying narrow-band imaging or magnifying chromoendoscopy help experienced endoscopists assess invasion depth of large sessile and flat polyps? Dig Dis Sci 2014; 59: $1520-1528$

[94] Ikematsu H, Matsuda T, Emura F et al. Efficacy of capillary pattern type IIIA/IIIB by magnifying narrow band imaging for estimating depth of invasion of early colorectal neoplasms. BMC Gastroenterol 2010; 10: 33

[95] Hayashi N, Tanaka S, Hewett DG et al. Endoscopic prediction of deep submucosal invasive carcinoma: validation of the narrow-band imaging international colorectal endoscopic (NICE) classification. Gastrointest Endosc 2013; 78: 625-632

[96] Hurlstone DP, Cross SS, Adam I et al. Endoscopic morphological anticipation of submucosal invasion in flat and depressed colorectal lesions: clinical implications and subtype analysis of the kudo type $\mathrm{V}$ pit pattern using high-magnification-chromoscopic colonoscopy. Colorectal Dis 2004; 6: $369-375$

[97] Tobaru T, Mitsuyama K, Tsuruta O et al. Sub-classification of type VI pit patterns in colorectal tumors: relation to the depth of tumor invasion. Int J Oncol 2008; 33: $503-508$ 
[98] Horie H, Togashi K, Kawamura Y] et al. Colonoscopic stigmata of 1 $\mathrm{mm}$ or deeper submucosal invasion in colorectal cancer. Dis Colon Rectum 2008; 51: 1529-1534

[99] Saito Y, Fujii T, Kondo H et al. Endoscopic treatment for laterally spreading tumors in the colon. Endoscopy 2001; 33: 682-686

[100] Uraoka T, Saito Y, Matsuda T et al. Endoscopic indications for endoscopic mucosal resection of laterally spreading tumours in the colorectum. Gut 2006; 55: $1592-1597$

[101] Kudo S, Tamura S, Nakajima T et al. Diagnosis of colorectal tumorous lesions by magnifying endoscopy. Gastrointest Endosc 1996; 44: $8-14$

[102] Haggitt RC, Glotzbach RE, Soffer EE et al. Prognostic factors in colorectal carcinomas arising in adenomas: implications for lesions removed by endoscopic polypectomy. Gastroenterology 1985; 89: $328-336$

[103] Nivatvongs S, Rojanasakul A, Reiman HM et al. The risk of lymph node metastasis in colorectal polyps with invasive adenocarcinoma. Dis Colon Rectum 1991; 34: 323-328

[104] Beaton C, Twine CP, Williams GL et al. Systematic review and metaanalysis of histopathological factors influencing the risk of lymph node metastasis in early colorectal cancer. Colorectal Dis 2013; 15 : $788-797$

[105] Moss A. From gastroenterologist to surgeon to gastroenterologist for management of large sessile colonic polyps: something new under the sun? Gastrointest Endosc 2014; 79: 108 -110

[106] Friedland S, Banerjee S, Kochar R et al. Outcomes of repeat colonoscopy in patients with polyps referred for surgery without biopsyproven cancer. Gastrointest Endosc 2014; 79: 101 - 107

[107] Kethu SR, Banerjee S, Desilets D et al. Endoscopic tattooing. Gastrointest Endosc 2010; 72: 681-685

[108] Askin MP, Waye JD, Fiedler L et al. Tattoo of colonic neoplasms in 113 patients with a new sterile carbon compound. Gastrointest Endosc 2002; 56: 339-342

[109] Moss A, Bourke M], Pathmanathan N. Safety of colonic tattoo with sterile carbon particle suspension: a proposed guideline with illustrative cases. Gastrointest Endosc 2011; 74: 214-218

[110] Park JW, Sohn DK, Hong CW et al. The usefulness of preoperative colonoscopic tattooing using a saline test injection method with prepackaged sterile India ink for localization in laparoscopic colorectal surgery. Surg Endosc 2008; 22: 501 - 505

[111] Ono S, Fujishiro M, Goto O et al. Endoscopic submucosal dissection for colonic laterally spreading tumors is difficult after target tattooing. Gastrointest Endosc 2009; 69: 763 - 766

[112] Elarini T, Wexner SD, Isenberg GA. The need for standardization of colonoscopic tattooing of colonic lesions. Dis Colon Rectum 2015; 58: $264-267$

[113] Moss A. Colonic tattooing: the revival of a black art? Gastrointest Endosc 2012; 76: 801-803

[114] Fu KI, Fujii T, Kato S et al. A new endoscopic tattooing technique for identifying the location of colonic lesions during laparoscopic surgery: a comparison with the conventional technique. Endoscopy 2001; 33: 687-691

[115] Kang HJ, Lee BI, Kim BW et al. Potential cancer cell inoculation of tattoo site through use of a contaminated needle. Gastrointest Endosc 2006; 63: 884-886

[116] Yeung JM, Maxwell-Armstrong C, Acheson AG. Colonic tattooing in laparoscopic surgery - making the mark? Colorectal Dis 2009; 11: $527-530$

[117] Ferrara F, Luigiano C, Ghersi S et al. Efficacy, safety and outcomes of "inject and cut" endoscopic mucosal resection for large sessile and flat colorectal polyps. Digestion 2010; 82: 213-220
[118] Lee T], Rees C], Nickerson C et al. Management of complex colonic polyps in the English Bowel Cancer Screening Programme. Br J Surg 2013; 100: $1633-1639$

[119] Kim HG, Thosani N, Banerjee $S$ et al. Effect of prior biopsy sampling, tattoo placement, and snare sampling on endoscopic resection of large nonpedunculated colorectal lesions. Gastrointest Endosc 2015; 81: 204-213

[120] Nanda KS, Tutticci N, Burgess NG et al. Endoscopic mucosal resection of laterally spreading lesions involving the ileocecal valve: technique, risk factors for failure, and outcomes. Endoscopy 2015; 47: $710-718$

[121] Holt BA, Bassan MS, Sexton A et al. Advanced mucosal neoplasia of the anorectal junction: endoscopic resection technique and outcomes (with videos). Gastrointest Endosc 2014; 79: 119-126

[122] Burgess NG, Metz AJ, Williams SJ et al. Risk factors for intraprocedural and clinically significant delayed bleeding after wide-field endoscopic mucosal resection of large colonic lesions. Clin Gastroenterol Hepatol 2014; 12: 651-661

[123] Hassan C, Repici A, Sharma P et al. Efficacy and safety of endoscopic resection of large colorectal polyps: a systematic review and metaanalysis. Gut 2016; 65: $806-820$

[124] Metz AJ, Bourke MJ, Moss A et al. Factors that predict bleeding following endoscopic mucosal resection of large colonic lesions. Endoscopy 2011; 43: 506-511

[125] Rutter MD, Nickerson C, Rees C] et al. Risk factors for adverse events related to polypectomy in the English Bowel Cancer Screening Programme. Endoscopy 2014; 46: 90-97

[126] Fujiya M, Tanaka K, Dokoshi T et al. Efficacy and adverse events of EMR and endoscopic submucosal dissection for the treatment of colon neoplasms: a meta-analysis of studies comparing EMR and endoscopic submucosal dissection. Gastrointest Endosc 2015; 81: $583-595$

[127] Chukmaitov A, Bradley C], Dahman B et al. Association of polypectomy techniques, endoscopist volume, and facility type with colonoscopy complications. Gastrointest Endosc 2013; 77: 436-446

[128] Heldwein W, Dollhopf M, Rosch T et al. The Munich Polypectomy Study (MUPS): prospective analysis of complications and risk factors in 4000 colonic snare polypectomies. Endoscopy 2005; 37: $1116-$ 1122

[129] Rabeneck L, Paszat LF, Hilsden R] et al. Bleeding and perforation after outpatient colonoscopy and their risk factors in usual clinical practice. Gastroenterology 2008; 135: 1899-1906, 1906 e1891

[130] Singh H, Penfold RB, DeCoster C et al. Colonoscopy and its complications across a Canadian regional health authority. Gastrointest Endosc 2009; 69: 665-671

[131] Gupta S, Miskovic D, Bhandari PS et al. A novel method for determining the difficulty of colonoscopic polypectomy. Frontline Gastroenterol 2013; 4: 244-248

[132] Burgess NG, Bahin FF, Bourke M]. Colonic polypectomy (with videos). Gastrointest Endosc 2015; 81: 813-835

[133] Holt BA, Bourke MJ. Wide field endoscopic resection for advanced colonic mucosal neoplasia: current status and future directions. Clin Gastroenterol Hepatol 2012; 10: 969-979

[134] Hwang JH, Konda V, Abu Dayyeh BK et al. Endoscopic mucosal resection. Gastrointest Endosc 2015; 82: 215-226

[135] Ferreira AO, Moleiro J, Torres J et al. Solutions for submucosal injection in endoscopic resection: a systematic review and meta-analysis. Endosc Int Open 2016; 4: E1 -E16

[136] Huai ZY, Feng Xian W, Chang Jiang L et al. Submucosal injection solution for endoscopic resection in gastrointestinal tract: a traditional and network meta-analysis. Gastroenterol Res Pract 2015; 2015: 702768 
[137] Moss A, Bourke M], Metz AJ. A randomized, double-blind trial of succinylated gelatin submucosal injection for endoscopic resection of large sessile polyps of the colon. Am J Gastroenterol 2010; 105: $2375-2382$

[138] Fasoulas K, Lazaraki G, Chatzimavroudis G et al. Endoscopic mucosal resection of giant laterally spreading tumors with submucosal injection of hydroxyethyl starch: comparative study with normal saline solution. Surg Laparosc Endosc Percutan Tech 2012; 22: 272 - 278

[139] Friedland S, Kothari S, Chen A et al. Endoscopic mucosal resection with an over-the-counter hyaluronate preparation. Gastrointest Endosc 2012; 75: 1040 - 1044

[140] Yamamoto H, Yahagi N, Oyama T et al. Usefulness and safety of $0.4 \%$ sodium hyaluronate solution as a submucosal fluid "cushion" in endoscopic resection for gastric neoplasms: a prospective multicenter trial. Gastrointest Endosc 2008; 67: 830-839

[141] Yoshida N, Naito Y, Inada Y et al. Endoscopic mucosal resection with $0.13 \%$ hyaluronic acid solution for colorectal polyps less than $20 \mathrm{~mm}$ : a randomized controlled trial. J Gastroenterol Hepatol 2012; 27: $1377-1383$

[142] Kishihara T, Chino A, Uragami N et al. Usefulness of sodium hyaluronate solution in colorectal endoscopic mucosal resection. Dig Endosc 2012; 24: 348-352

[143] Oka S, Tanaka S, Saito Y et al. Local recurrence after endoscopic resection for large colorectal neoplasia: a multicenter prospective study in Japan. Am J Gastroenterol 2015; 110: 697-707

[144] Uraoka T, Saito Y, Yamamoto K et al. Submucosal injection solution for gastrointestinal tract endoscopic mucosal resection and endoscopic submucosal dissection. Drug Des Devel Ther 2009; 2: 131 138

[145] Matsui Y, Inomata M, Izumi K et al. Hyaluronic acid stimulates tumor-cell proliferation at wound sites. Gastrointest Endosc 2004; 60: $539-543$

[146] Uraoka T, Fujii T, Saito Y et al. Effectiveness of glycerol as a submucosal injection for EMR. Gastrointest Endosc 2005; 61: 736 - 740

[147] Feitoza AB, Gostout C], Burgart LJ et al. Hydroxypropyl methylcellulose: A better submucosal fluid cushion for endoscopic mucosal resection. Gastrointest Endosc 2003; 57: $41-47$

[148] Arezzo A, Pagano N, Romeo F et al. Hydroxy-propyl-methyl-cellulose is a safe and effective lifting agent for endoscopic mucosal resection of large colorectal polyps. Surg Endosc 2009; 23: 1065-1069

[149] Bacani C], Woodward TA, Raimondo M et al. The safety and efficacy in humans of endoscopic mucosal resection with hydroxypropyl methylcellulose as compared with normal saline. Surg Endosc 2008; 22: $2401-2406$

[150] Woodward T, Crook JE, Raimondo M et al. Improving complete EMR of colorectal neoplasia: a randomized trial comparing snares and injectate in the resection of large sessile colon polyps. Gastrointest Endosc 2015; 81: 673-681

[151] Katsinelos P, Kountouras J, Paroutoglou G et al. A comparative study of $50 \%$ dextrose and normal saline solution on their ability to create submucosal fluid cushions for endoscopic resection of sessile rectosigmoid polyps. Gastrointest Endosc 2008; 68: 692-698

[152] Varadarajulu S, Tamhane A, Slaughter RL. Evaluation of dextrose 50\% as a medium for injection-assisted polypectomy. Endoscopy 2006; 38: $907-912$

[153] Hurlstone DP, Fu KI, Brown SR et al. EMR using dextrose solution versus sodium hyaluronate for colorectal Paris type I and 0 -II lesions: a randomized endoscopist-blinded study. Endoscopy 2008; 40: $110-114$

[154] Fujishiro M, Yahagi N, Kashimura K et al. Tissue damage of different submucosal injection solutions for EMR. Gastrointest Endosc 2005; 62: $933-942$
[155] Jung YS, Park DI. Submucosal injection solutions for endoscopic mucosal resection and endoscopic submucosal dissection of gastrointestinal neoplasms. Gastrointestinal Intervention 2013; 2: $73-77$

[156] Al-Taie OH, Bauer Y, Dietrich CG et al. Efficacy of submucosal injection of different solutions inclusive blood components on mucosa elevation for endoscopic resection. Clin Exp Gastroenterol 2012; 5: 43-48

[157] Holt BA, Jayasekeran V, Sonson R et al. Topical submucosal chromoendoscopy defines the level of resection in colonic EMR and may improve procedural safety (with video). Gastrointest Endosc 2013; 77: 949-953

[158] Tajika M, Niwa Y, Bhatia V et al. Comparison of endoscopic submucosal dissection and endoscopic mucosal resection for large colorectal tumors. Eur J Gastroenterol Hepatol 2011; 23: 1042 - 1049

[159] Puli SR, Kakugawa Y, Gotoda T et al. Meta-analysis and systematic review of colorectal endoscopic mucosal resection. World J Gastroenterol 2009; 15: $4273-4277$

[160] Bourke M. Current status of colonic endoscopic mucosal resection in the west and the interface with endoscopic submucosal dissection. Dig Endosc 2009; 21: (Suppl. 01): S22-27

[161] Moss A, Bourke MJ, Tran K et al. Lesion isolation by circumferential submucosal incision prior to endoscopic mucosal resection (CSIEMR) substantially improves en bloc resection rates for $40-\mathrm{mm}$ coIonic lesions. Endoscopy 2010; 42: 400-404

[162] Yoshida N, Saito Y, Hirose R et al. Endoscopic mucosal resection for middle and large colorectal polyps with a double-loop snare. Digestion 2014; 90: 232-239

[163] Binmoeller KF, Weilert F, Shah J et al. “Underwater" EMR without submucosal injection for large sessile colorectal polyps (with video). Gastrointest Endosc 2012; 75: 1086 - 1091

[164] Brooker JC, Saunders BP, Shah SG et al. Treatment with argon plasma coagulation reduces recurrence after piecemeal resection of large sessile colonic polyps: a randomized trial and recommendations. Gastrointest Endosc 2002; 55: 371 - 375

[165] Albuquerque W, Arantes VN, Coelho LG et al. Complementation by argon plasma coagulation after endoscopic piecemeal resection of large colorectal adenomas. Rev Col Bras Cir 2013; 40: 404- 408

[166] Neneman B, Gasiorowska A, Malecka-Panas E. The efficacy and safety of argon plasma coagulation (APC) in the management of polyp remnants in stomach and colon. Adv Med Sci 2006; 51: 88-93

[167] Han KS, Sohn DK, Choi DH et al. Prolongation of the period between biopsy and EMR can influence the nonlifting sign in endoscopically resectable colorectal cancers. Gastrointest Endosc 2008; 67: 97 102

[168] Uno Y, Munakata A. The non-lifting sign of invasive colon cancer. Gastrointest Endosc 1994; 40: 485-489

[169] Ishiguro A, Uno Y, Ishiguro Y et al. Correlation of lifting versus nonlifting and microscopic depth of invasion in early colorectal cancer. Gastrointest Endosc 1999; 50: 329-333

[170] Kato H, Haga S, Endo S et al. Lifting of lesions during endoscopic mucosal resection (EMR) of early colorectal cancer: implications for the assessment of resectability. Endoscopy 2001; 33: 568- 573

[171] Kobayashi N, Saito Y, Sano Y et al. Determining the treatment strategy for colorectal neoplastic lesions: endoscopic assessment or the non-lifting sign for diagnosing invasion depth? Endoscopy 2007; 39: $701-705$

[172] Tanaka S, Kashida H, Saito Y et al. JGES guidelines for colorectal endoscopic submucosal dissection/endoscopic mucosal resection. Dig Endosc 2015; 27: 417-434

[173] Oxenberg J, Hochwald SN, Nurkin S. Ablative therapies for colorectal polyps and malignancy. Biomed Res Int 2014; 2014: 986352 
[174] Miller K, Waye JD. Polyp retrieval after colonoscopic polypectomy: use of the Roth Retrieval Net. Gastrointest Endosc 2001; 54: 505 507

[175] Rey JF, Beilenhoff U, Neumann CS et al. European Society of Gastrointestinal Endoscopy (ESGE) guideline: the use of electrosurgical units. Endoscopy 2010; 42: 764-772

[176] Tokar JL, Barth BA, Banerjee S et al. Electrosurgical generators. Gastrointest Endosc 2013; 78: 197 - 208

[177] Singh N, Harrison M, Rex DK. A survey of colonoscopic polypectomy practices among clinical gastroenterologists. Gastrointest EndosC 2004; 60: $414-418$

[178] Carter D, Beer-Gabel M, Zbar A et al. A survey of colonoscopic polypectomy practice amongst Israeli gastroenterologists. Ann Gastroenterol 2013; 26: $135-140$

[179] Chino A, Karasawa T, Uragami N et al. A comparison of depth of tissue injury caused by different modes of electrosurgical current in a pig colon model. Gastrointest Endosc 2004; 59: 374 - 379

[180] Van Gossum A, Cozzoli A, Adler M et al. Colonoscopic snare polypectomy: analysis of 1485 resections comparing two types of current. Gastrointest Endosc 1992; 38: 472 - 475

[181] Parra-Blanco A, Kaminaga N, Kojima T et al. Colonoscopic polypectomy with cutting current: is it safe? Gastrointest Endosc 2000; 51: $676-681$

[182] Wu J, Hu B. The role of carbon dioxide insufflation in colonoscopy: a systematic review and meta-analysis. Endoscopy 2012; 44: 128 136

[183] Hsu WF, Hu WH, Chen YN et al. Carbon dioxide insufflation can significantly reduce toilet use after colonoscopy: a double-blind randomized controlled trial. Endoscopy 2014; 46: 190 - 195

[184] Bassan MS, Holt B, Moss A et al. Carbon dioxide insufflation reduces number of postprocedure admissions after endoscopic resection of large colonic lesions: a prospective cohort study. Gastrointest Endosc 2013; 77: $90-95$

[185] Fahrtash-Bahin F, Holt BA, Jayasekeran V et al. Snare tip soft coagulation achieves effective and safe endoscopic hemostasis during wide-field endoscopic resection of large colonic lesions (with videos). Gastrointest Endosc 2013; 78: 158-163. e1

[186] Baron TH, Song LM, Ross A et al. Use of an over-the-scope clipping device: multicenter retrospective results of the first U.S. experience (with videos). Gastrointest Endosc 2012; 76: 202 - 208

[187] Shioji K, Suzuki Y, Kobayashi M et al. Prophylactic clip application does not decrease delayed bleeding after colonoscopic polypectomy. Gastrointest Endosc 2003; 57: 691 - 694

[188] Liaquat H, Rohn E, Rex DK. Prophylactic clip closure reduced the risk of delayed postpolypectomy hemorrhage: experience in 277 clipped large sessile or flat colorectal lesions and 247 control lesions. Gastrointest Endosc 2013; 77: 401 - 407

[189] Bahin FF, Naidoo M, Williams S] et al. Prophylactic endoscopic coagulation to prevent bleeding after wide-field endoscopic mucosal resection of large sessile colon polyps. Clin Gastroenterol Hepatol 2015; 13: $724-730$

[190] Gandhi S, Narula N, Mosleh W et al. Meta-analysis: colonoscopic post-polypectomy bleeding in patients on continued clopidogrel therapy. Aliment Pharmacol Ther 2013; 37: 947 - 952

[191] Parikh ND, Zanocco K, Keswani RN et al. A cost-efficacy decision analysis of prophylactic clip placement after endoscopic removal of large polyps. Clin Gastroenterol Hepatol 2013; 11: 1319-1324

[192] Friedland S, Soetikno R. Colonoscopy with polypectomy in anticoagulated patients. Gastrointest Endosc 2006; 64: 98-100

[193] Bahin FF, Rasouli KN, Byth K et al. Prediction of clinically significant bleeding following wide-field endoscopic resection of large sessile and laterally spreading colorectal lesions: a clinical risk score. Am J Gastroenterol 2016; 111: 1115-1122
[194] Ron-Tal Fisher O, Gralnek IM, Eisen GM et al. Endoscopic hemostasis is rarely used for hematochezia: a population-based study from the Clinical Outcomes Research Initiative National Endoscopic Database. Gastrointest Endosc 2014; 79: 317 - 325

[195] Church J. Complications of colonoscopy. Gastroenterol Clin North Am 2013; 42: 639-657

[196] Strate LL, Gralnek IM. ACG Clinical Guideline: Management of patients with acute lower gastrointestinal bleeding. Am J Gastroenterol 2016; 111: 459-474

[197] Jensen DM, Machicado GA, Jutabha R et al. Urgent colonoscopy for the diagnosis and treatment of severe diverticular hemorrhage. $\mathrm{N}$ Engl J Med 2000; 342: 78-82

[198] Sonnenberg A. Management of delayed postpolypectomy bleeding: a decision analysis. Am J Gastroenterol 2012; 107: 339-342

[199] Burgess NG, Williams SJ, Hourigan LF et al. A management algorithm based on delayed bleeding after wide-field endoscopic mucosal resection of large colonic lesions. Clin Gastroenterol Hepatol 2014; 12: $1525-1533$

[200] Parra-Blanco A, Kaminaga N, Kojima T et al. Hemoclipping for postpolypectomy and postbiopsy colonic bleeding. Gastrointest Endosc 2000; $51: 37-41$

[201] Paspatis GA, Vardas E, Theodoropoulou A et al. Complications of colonoscopy in a large public county hospital in Greece. A 10-year study. Dig Liver Dis 2008; 40: 951 - 957

[202] Slivka A, Parsons WG, Carr-Locke DL. Endoscopic band ligation for treatment of post-polypectomy hemorrhage. Gastrointest Endosc 1994; 40: $230-232$

[203] Smith RE, Doull ]. Treatment of colonic post-polypectomy bleeding site by endoscopic band ligation. Gastrointest Endosc 1994; 40: $499-500$

[204] Paspatis GA, Dumonceau JM, Barthet $M$ et al. Diagnosis and management of iatrogenic endoscopic perforations: European Society of Gastrointestinal Endoscopy (ESGE) Position Statement. Endoscopy 2014; 46: $693-711$

[205] Adler A, Lieberman D, Aminalai A et al. Data quality of the German screening colonoscopy registry. Endoscopy 2013; 45: 813-818

[206] Burgess NG, Bassan MS, McLeod D et al. Deep mural injury and perforation after colonic endoscopic mucosal resection: a new classification and analysis of risk factors. Gut 2016: , Jul 27. pii: gutjnl2015-309848. doi: DOI: 10.1136/gutjnl-2015-309848 Epub ahead of print

[207] von Karsa L, Patnick J, Segnan N et al. European guidelines for quality assurance in colorectal cancer screening and diagnosis: overview and introduction to the full supplement publication. Endoscopy 2013; 45: $51-59$

[208] Quirke P, Risio M, Lambert R et al. Quality assurance in pathology in colorectal cancer screening and diagnosis - European recommendations. Virchows Archiv 2011; 458: 1 -19

[209] Vieth M, Quirke P, Lambert R et al. Annex to Quirke et al. Quality assurance in pathology in colorectal cancer screening and diagnosis: annotations of colorectal lesions. Virchows Archiv 2011; 458: 21 - 30

[210] Vieth M, Quirke P, Lambert R et al. European guidelines for quality assurance in colorectal cancer screening and diagnosis. First edition - Annotations of colorectal lesions. Endoscopy 2012; 44: (Suppl. 03): SE131-139

[211] Hamilton SR, Bosman FT, Boffetta P et al. Carcinoma of the colon and rectum. In: Bosman FT, Carneiro F, Hruban RH, Theise ND, eds. WHO classification of tumours of the digestive system. 4th edn. Lyon: IARC; 2010: 134-146

[212] Langner C. Serrated and non-serrated precursor lesions of colorectal cancer. Dig Dis 2015; 33: 28-37 
[213] Rex DK, Ahnen DJ, Baron JA et al. Serrated lesions of the colorectum: review and recommendations from an expert panel. Am J Gastroenterol 2012; 107: 1315-1329; quiz 1314, 1330

[214] Bettington M, Walker N, Clouston A et al. The serrated pathway to colorectal carcinoma: current concepts and challenges. Histopathology 2013; 62: 367-386

[215] Hazewinkel Y, de Wijkerslooth TR, Stoop EM et al. Prevalence of serrated polyps and association with synchronous advanced neoplasia in screening colonoscopy. Endoscopy 2014; 46: 219-224

[216] Snover DC. Update on the serrated pathway to colorectal carcinoma. Hum Pathol 2011; 42: 1 - 10

[217] Ensari A, Bilezikci B, Carneiro F et al. Serrated polyps of the colon: how reproducible is their classification? Virchows Archiv 2012; 461: 495-504

[218] Rau TT, Agaimy A, Gehoff A et al. Defined morphological criteria allow reliable diagnosis of colorectal serrated polyps and predict polyp genetics. Virchows Archiv 2014; 464: 663-672

[219] Bettington ML, Walker NI, Rosty C et al. A clinicopathological and molecular analysis of 200 traditional serrated adenomas. Mod Pathol 2015; $28: 414-427$

[220] Bettington ML, Chetty R. Traditional serrated adenoma: an update. Hum Pathol 2015; 46: 933 - 938

[221] Resch A, Langner C. Risk assessment in early colorectal cancer: histological and molecular markers. Dig Dis 2015; 33: 77- 85

[222] Kikuchi R, Takano M, Takagi K et al. Management of early invasive colorectal cancer. Risk of recurrence and clinical guidelines. Dis CoIon Rectum 1995; 38: 1286-1295

[223] Williams JG, Pullan RD, Hill J et al. Management of the malignant colorectal polyp: ACPGBI position statement. Colorectal Dis 2013; 15: (Suppl. 02): 1-38

[224] Bosch SL, Teerenstra S, de Wilt JH et al. Predicting lymph node metastasis in PT1 colorectal cancer: a systematic review of risk factors providing rationale for therapy decisions. Endoscopy 2013; 45: $827-834$

[225] Ueno H, Mochizuki H, Hashiguchi Y et al. Risk factors for an adverse outcome in early invasive colorectal carcinoma. Gastroenterology 2004; 127: $385-394$

[226] Brown IS, Bettington ML, Bettington A et al. Adverse histological features in malignant colorectal polyps: a contemporary series of 239 cases. J Clin Pathol 2016; 69: 292-299

[227] Hassan C, Zullo A, Risio M et al. Histologic risk factors and clinical outcome in colorectal malignant polyp: a pooled-data analysis. Dis Colon Rectum 2005; 48: 1588-1596

[228] Resch A, Schneider NI, Langner C. Pathological evaluation of colorectal cancer specimens: advanced and early lesions. Cesk Patol 2015; 51: $12-22$

[229] Gunderson LL, Jessup JM, Sargent DJ et al. Revised TN categorization for colon cancer based on national survival outcomes data. J Clin Oncol 2010; 28: 264-271

[230] Macias-Garcia F, Celeiro-Munoz C, Lesquereux-Martinez L et al. A clinical model for predicting lymph node metastasis in submucosal invasive (T1) colorectal cancer. Int J Colorectal Dis 2015; 30: 761 768

[231] Pollard CW, Nivatvongs S, Rojanasakul A et al. The fate of patients following polypectomy alone for polyps containing invasive carcinoma. Dis Colon Rectum 1992; 35: 933 - 937

[232] Matsuda T, Fukuzawa M, Uraoka T et al. Risk of lymph node metastasis in patients with pedunculated type early invasive colorectal cancer: a retrospective multicenter study. Cancer Sci 2011; 102: $1693-1697$

[233] Nascimbeni R, Burgart LJ, Nivatvongs S et al. Risk of lymph node metastasis in T1 carcinoma of the colon and rectum. Dis Colon Rectum 2002; 45: $200-206$
[234] Toh EW, Brown P, Morris E et al. Area of submucosal invasion and width of invasion predicts lymph node metastasis in PT1 colorectal cancers. Dis Colon Rectum 2015; 58: 393-400

[235] Choi JY, Jung SA, Shim KN et al. Meta-analysis of predictive clinicopathologic factors for lymph node metastasis in patients with early colorectal carcinoma. J Korean Med Sci 2015; 30: 398-406

[236] Mou S, Soetikno R, Shimoda T et al. Pathologic predictive factors for lymph node metastasis in submucosal invasive (T1) colorectal cancer: a systematic review and meta-analysis. Surg Endosc 2013; 27: $2692-2703$

[237] Wada H, Shiozawa M, Katayama K et al. Systematic review and metaanalysis of histopathological predictive factors for lymph node metastasis in T1 colorectal cancer. J Gastroenterol 2015; 50: 727-734

[238] Kawaura K, Fujii S, Murata Y et al. The lymphatic infiltration identified by D2-40 monoclonal antibody predicts lymph node metastasis in submucosal invasive colorectal cancer. Pathobiology 2007; 74: $328-335$

[239] Chandler I, Houlston RS. Interobserver agreement in grading of colorectal cancers-findings from a nationwide web-based survey of histopathologists. Histopathology 2008; 52: 494-499

[240] Choi DH, Sohn DK, Chang H] et al. Indications for subsequent surgery after endoscopic resection of submucosally invasive colorectal carcinomas: a prospective cohort study. Dis Colon Rectum 2009; 52: 438-445

[241] Tateishi Y, Nakanishi Y, Taniguchi $\mathrm{H}$ et al. Pathological prognostic factors predicting lymph node metastasis in submucosal invasive (T1) colorectal carcinoma. Mod Pathol 2010; 23: 1068-1072

[242] Wang LM, Kevans D, Mulcahy $\mathrm{H}$ et al. Tumor budding is a strong and reproducible prognostic marker in T3N0 colorectal cancer. Am J Surg Pathol 2009; 33: $134-141$

[243] Hase K, Shatney C, Johnson D et al. Prognostic value of tumor "budding" in patients with colorectal cancer. Dis Colon Rectum 1993; 36: $627-635$

[244] Hackelsberger A, Fruhmorgen P, Weiler $\mathrm{H}$ et al. Endoscopic polypectomy and management of colorectal adenomas with invasive carcinoma. Endoscopy 1995; 27: $153-158$

[245] Coverlizza S, Risio M, Ferrari A et al. Colorectal adenomas containing invasive carcinoma. Pathologic assessment of lymph node metastatic potential. Cancer 1989; 64: 1937-1947

[246] Morson BC, Whiteway JE, Jones EA et al. Histopathology and prognosis of malignant colorectal polyps treated by endoscopic polypectomy. Gut 1984; 25: 437-444

[247] Naqvi S, Burroughs S, Chave HS et al. Management of colorectal polyp cancers. Ann R Coll Surg Engl 2012; 94: 574-578

[248] Butte JM, Tang P, Gonen M et al. Rate of residual disease after complete endoscopic resection of malignant colonic polyp. Dis Colon Rectum 2012; 55: $122-127$

[249] Cooper HS, Deppisch LM, Gourley WK et al. Endoscopically removed malignant colorectal polyps: clinicopathologic correlations. Gastroenterology 1995; 108: 1657-1665

[250] Netzer P, Binek J, Hammer B et al. Significance of histologic criteria for the management of patients with malignant colorectal polyps and polypectomy. Scand J Gastroenterol 1997; 32: 910 - 916

[251] Volk EE, Goldblum JR, Petras RE et al. Management and outcome of patients with invasive carcinoma arising in colorectal polyps. Gastroenterology 1995; 109: 1801-1807

[252] Kitajima K, Fujimori T, Fujii S et al. Correlations between lymph node metastasis and depth of submucosal invasion in submucosal invasive colorectal carcinoma: a Japanese collaborative study. J Gastroenterol 2004; 39: $534-543$

[253] Seitz U, Bohnacker S, Seewald S et al. Is endoscopic polypectomy an adequate therapy for malignant colorectal adenomas? Presentation 
of 114 patients and review of the literature. Dis Colon Rectum 2004; 47: 1789-1796; discussion 1796-1787

[254] Cunningham KN, Mills LR, Schuman BM et al. Long-term prognosis of well-differentiated adenocarcinoma in endoscopically removed colorectal adenomas. Dig Dis Sci 1994; 39: $2034-2037$

[255] Jass JR. Malignant colorectal polyps. Gastroenterology 1995; 109 : 2034-2035
[256] Quirke P, Risio M, Lambert R et al. European guidelines for quality assurance in colorectal cancer screening and diagnosis. First edition - Quality assurance in pathology in colorectal cancer screening and diagnosis. Endoscopy 2012; 44: (Suppl. 03): SE116 - 130

[257] National Institute for Health Care Excellence. Colorectal cancer: the diagnosis and management of colorectal cancer. National Institute for Health Care Excellence (NICE) Guideline. Available at: https:// www.nice.org.uk/Guidance/cg131 